\title{
Multi-temporal LiDAR and Landsat quantification of fire- induced changes to forest structure
}

T. Ryan McCarley ${ }^{\text {a }}$, Crystal A. Kolden ${ }^{b}, *$, Nicole M. Vaillant ${ }^{c}$, Andrew T. Hudak ${ }^{\mathrm{d}}$, Alistair M.S. Smith ${ }^{\mathrm{b}}$, Brian M. Wing ${ }^{\mathrm{e}}$, Bryce Kellogg ${ }^{\mathrm{f}}$, Jason Kreitler ${ }^{\mathrm{g}}$

${ }^{a}$ University of Idaho, Department of Geography, Moscow, ID, 83844, USA

${ }^{\mathrm{b}}$ University of Idaho, Department of Forest, Rangeland, and Fire Sciences, Moscow, ID, 83843, USA

${ }^{\mathrm{c}}$ USDA Forest Service, Pacific Northwest Research Station, Western Wildland Environmental Threat Assessment Center, Prineville, OR, 97754, USA

${ }^{\mathrm{d}}$ USDA Forest Service, Rocky Mountain Research Station, Moscow, ID, 83843, USA

${ }^{\mathrm{e}}$ USDA Forest Service, Pacific Southwest Research Station, Redding, CA, 96002, USA

${ }^{\mathrm{f}}$ The Nature Conservancy, Bend, OR, 97702, USA

${ }^{\mathrm{g}}$ USGS, Western Geographic Science Center, Boise, ID, 83706, USA

* Corresponding author. E-mail: ckolden@ uidaho.edu; Tel.: +1-208-885-6018.

\begin{abstract}
Measuring post-fire effects at landscape scales is critical to an ecological understanding of wildfire effects. Predominantly this is accomplished with either multi-spectral remote sensing data or through ground-based field sampling plots. While these methods are important, field data is usually limited to opportunistic post-fire observations, and spectral data often lacks validation with specific variables of change. Additional uncertainty remains regarding how best to account for environmental variables influencing fire effects (e.g., weather) for which observational data cannot easily be acquired, and whether pre-fire agents of change such as bark beetle and timber harvest impact model accuracy. This study quantifies wildfire effects by correlating changes in forest structure derived from multi-temporal Light Detection and Ranging (LiDAR) acquisitions to multi-temporal spectral changes captured by the Landsat Thematic Mapper and Operational Land Imager for the 2012 Pole Creek Fire in central Oregon. Spatial regression modeling was assessed as a methodology to account for spatial autocorrelation, and model consistency was
\end{abstract}


quantified across areas impacted by pre-fire mountain pine beetle and timber harvest. The strongest relationship $\left(\right.$ pseudo- $\mathrm{r}^{2}=0.86, \mathrm{p}<0.0001$ ) was observed between the ratio of shortwave infrared and near infrared reflectance (d74) and LiDAR-derived estimate of canopy cover change. Relationships between percentage of LiDAR returns in forest strata and spectral indices generally increased in strength with strata height. Structural measurements made closer to the ground were not well correlated. The spatial regression approach improved all relationships, demonstrating its utility, but model performance declined across pre-fire agents of change, suggesting that such studies should stratify by pre-fire forest condition. This study establishes that spectral indices such as d74 and dNBR are most sensitive to wildfire-caused structural changes such as reduction in canopy cover and perform best when that structure has not been reduced pre-fire.

Keywords: wildfire, eastern Cascades, dNBR, d74, canopy cover, simultaneous autoregression

\section{Introduction}

Remote sensing plays a critical role in allowing resource managers and scientists to assess fire effects across landscapes (Lentile et al., 2006). The quantification of fire effects is critical to understanding ecological impacts of fire, including evaluating ecosystem rehabilitation needs (Hessburg et al., 2015; Turner et al., 1994), mitigating secondary fire effects (e.g., flooding and erosion) (Moody et al., 2008; Robichaud et al., 2009), monitoring anomalies and trends in ecological recovery (Cansler \& Mckenzie, 2014; Eidenshink et al., 2007; Miller et al., 2009), and quantifying carbon balance (Meigs et al., 2009; Randerson et al., 2012). In light of the observed and projected increases in wildfire activity under anthropogenic climate change (Abatzoglou \& 
Williams, 2016; Barbero et al., 2015 et al), the ability to accurately quantify long-term carbon stocks is necessary for understanding biosphere-atmosphere feedbacks (Li et al., 2014). However, accurate spatiotemporal quantification of fire effects has been a key limitation, which the remote sensing community has worked to address. While considerable advances have been made in relating observed changes associated with fire effects to remote sensing data (Disney et al., 2011; Lentile et al., 2006; Smith et al., 2016b), there are still knowledge gaps and several known sources of uncertainty that can lead to extensive errors when applied to regional assessments (Kolden et al., 2015; Roy et al., 2006; Smith et al., 2016b).

Most notably, considerable disconnects exist between burn severity maps produced from relatively high-resolution, passive, spectral reflectance data, and observed fire-induced changes in forest structure that are readily related to aboveground carbon stocks and other metrics of interest to the broader science community (Kolden et al., 2015; Lentile et al., 2006). The products developed through the transformation of post-fire reflectance data to spectral indices are interpreted as burn severity, a term that does not currently have an agreed-upon biometric definition (Keeley, 2009; Lentile et al., 2006). These products frequently include the Normalized Burn Ratio, delta NBR (dNBR; Key \& Benson, 2006), and the Relative dNBR(RdNBR; Miller $\&$ Thode, 2007); the latter two indices are calculated as a national United States product by the Monitoring Trends in Burn Severity (MTBS) project (Eidenshink et al., 2007). Burn severity maps are useful for a range of management needs, and have been widely utilized for operational burned area rehabilitation efforts. However, they have also been used for research efforts that require more robust data inputs, such as to model pyrogenic emissions (Meigs et al., 2011), despite limited mechanistic validation of the products (Kolden et al., 2015; Sparks et al., 2015). 
The primary measure utilized to calibrate such indices and products is the Composite Burn Index (CBI) (Key \& Benson, 2006), a set of observations of surface changes inferred without pre-fire data and subject to several limitations (Lentile et al., 2009). Measurements are ocularly estimated (Lentile et al., 2009; Morgan et al., 2014; Zhu et al., 2006), and are aggregated across vertical strata to a comprehensive, unitless severity score that correlates poorly to both individual biometrics of interest and spectral reflectance of the top-most surface (De Santis \& Chuvieco, 2007; Hudak et al., 2007). CBI protocol includes subjectively reconstructing estimates of pre-fire conditions in the post-fire environment based on unburned areas in the vicinity of the plot (i.e., no pre-fire data are collected), but it suggests placing plots amidst relatively homogeneous areas of fire severity. In stand-replacing fire regimes it is not uncommon to have plots fall amid large areas of high severity with no nearby indicators of pre-fire condition. This approach was developed for management needs and provides data sufficient for many management applications, but also yields data of unknown accuracy that are extremely difficult, if not impossible, to verify (Lentile et al., 2006; Morgan et al., 2014; Smith et al., 2016b; Zhu et al., 2006). CBI has been the standard for burn severity assessment for over a decade, but as new data types become available (e.g., LiDAR) and more existing field plots are burned in fires, more robust field methods should be developed to overcome CBI limitations.

The difficulty in quantifying fire-induced change without pre-fire measurements extends beyond the CBI protocol. There have been a few research opportunities where fire burned through permanent monitoring plots that were subsequently assessed (Bishop et al., 2014; Cocke et al., 2005; Lutz et al., 2016; Wimberly \& Reilly, 2007); however, these studies have relied on small numbers of burned plots to represent change over a large area. Long-term monitoring plots associated with the Forest Inventory and Analysis (FIA) project (Gillespie, 1999) have burned 
with greater frequency in recent years, but the re-measurement intervals between FIA collections (5-10 years) can lead to considerable disconnects between the fire event and the post-fire re-visit, reducing the visibility and magnitude of those effects when data collection does occur (Whittier $\&$ Gray, 2016). The lack of pre-fire observations for the majority of field data utilized to calibrate burn severity spectral indices leads to inconsistency between the remote sensing measures that quantify change between pre- and post-fire acquisitions and field calibration measures that are limited to post-fire observations (Smith et al., 2016). Measuring only the postfire environment cannot adequately represent the effects of fire, because it fails to capture the magnitude of change, whether the observed changes are in fact directly caused by the fire, or if another disturbance event is also contributing (Roy et al., 2013; Smith et al., 2010; Smith et al., 2016b). Without the development of physical linkages between spectral data and quantitative measures of forest structure, errors in carbon quantification will extrapolate through models, propagating errors (Kolden et al., 2015); to-date, only a limited number of studies have sought to relate radiometric datasets to mechanistic changes in vegetation following fires (Chuvieco et al., 2006; De Santis et al., 2009; De Santis \& Chuvieco, 2007; Disney et al., 2011; Smith et al., 2016b).

The increasing acquisition frequency of airborne Light Detection and Ranging (LiDAR) data over relatively large areas offers a potential alternative mode of measuring fire-induced ecological change and calibrating reflectance-based spectral indices to improve the models that use index-based products. It has been well demonstrated in the remote sensing literature that discrete-return LiDAR collected at high spatial resolution can accurately measure forest height, percent canopy cover, and provide three-dimensional canopy height and density metrics describing the vertical distribution of canopy material, aerodynamic roughness (Hudak et al., 
2009; Lefsky et al., 2002; Smith et al., 2009), and gap size (Hudak et al., 2009; Kane et al., 2013). Analyzed in concert with field data, LiDAR returns can also be used to predict forest structure attributes such as basal area, volume, biomass, and leaf area (García et al., 2010; Hudak et al., 2009; Lefsky et al., 2002). LiDAR has been successfully used to quantify the effects of insect outbreaks in forests (Bater et al., 2010; Bright et al., 2012), pre-fire fuel loading (Andersen et al., 2005; García et al., 2011; Riaño et al., 2003, 2004; Seielstad \& Queen, 2003), and structural measurements of the post-fire environment (Bishop et al., 2014; Kane et al., 2013, 2014; Kwak et al., 2010; Wulder et al., 2009). Structural datasets such as those derived from LiDAR data have been previously highlighted as holding considerable promise for directly quantifying changes in vegetation structure (Smith et al., 2014), but acquisitions of highresolution, comparable pre- and post- fire LiDAR data that provide measure of fire-induced vegetation change have been limited (Bishop et al., 2014; Reddy et al., 2015; Wang \& Glenn, 2009; Wulder et al., 2009). However, multi-temporal LiDAR is not a novel concept and has been widely applied to quantify other ecosystem properties such as snow volume (Tinkham et al., 2014), forest growth and harvest disturbance (Hudak et al., 2012), boreal forest gap dynamics (Vepakomma et al., 2008), and change in biomass resulting from a Gypsum moth (Lymantria dispar) outbreak (Skowronski et al., 2014), among other applications.

The comparison of structural changes in vegetation derived from multi-temporal LiDAR and spectral indices used to characterize burn severity is relatively novel. To-date, only two known studies have been able to spatially match pre- and post-fire LiDAR acquisitions in order to objectively quantify fire effects on forest structure (Bishop et al., 2014; Wulder et al., 2009), with additional studies by Wang \& Glenn (2009) focused on shrubs in steppe ecosystems and Reddy et al. (2015) in peatlands. Neither of the prior studies in forest ecosystems explicitly 
linked LiDAR-derived forest structure metrics to the spectral indices that are most commonly used to assess forest burn severity across an entire fire; Bishop et al. (2014) assessed the Normalized Differenced Vegetation Index (NDVI) on a small portion of a wildfire, while Wulder et al. (2009) analyzed only a limited set of returns from a single LiDAR transect. There is an urgent need to contextualize unitless spectral indices that are widely-utilized to characterize burn severity and model emissions (e.g., dNBR and RdNBR) with specific environmental changes such as vegetative structure. Multi-temporal LiDAR presents arguably one of the best sources of contiguous forest structural data across large geographical areas, emphasizing the critical need for additional studies where pre- and post-fire LiDAR overlap.

One such opportunity arose following the 2012 Pole Creek Fire in Central Oregon, USA, where post-fire LiDAR was acquired spatially coincident with a pre-fire acquisition across an entire fire, featuring a gradient of forest types. Pre-fire LiDAR had been acquired in 2009 after mountain pine beetle (Dendroctonus ponderosae) caused extensive tree mortality throughout the upper elevation lodgepole pine stands approximately a decade before the fire (Agne et al., 2016; McCarley, 2016). As no prior studies have assessed the impacts of insect outbreaks on the relationships between spectral indices of burn severity and validation data, this presented a particularly unique research opportunity.

The overarching objective of this study was to assess the ability of spectral indices derived from Landsat imagery to predict biophysical changes in forest structure inferred from pre- and post-fire LiDAR data. Specifically, the authors sought to 1) quantify relationships between several common fire effects spectral indices and a suite of LiDAR-derived forest structure metrics to identify the strongest relationships, 2) characterize the impacts of the pre-fire insect outbreak and forest management on model performance, and 3) assess whether integrating 
spatial autocorrelation improved the relationships between spectral indices and LiDAR metrics, following Prichard \& Kennedy (2014).

\section{Material and methods}

\subsection{Study area}

The Pole Creek Fire occurred along the eastern Cascade Mountains in the Deschutes National Forest, approximately 30 kilometers west of Bend, Oregon (Figure 1). Ignited by lightning on September $9^{\text {th }}, 2012$, the fire grew to 10,800 hectares before containment in midOctober. The fire burned across a large elevational gradient (1,200 to 2,100 meters) and wide variety of forest types, with dominant tree species including ponderosa pine (Pinus ponderosa), lodgepole pine (Pinus contorta), mountain hemlock (Tsuga mertensiana), and grand fir (Abies grandis). Forest canopy is mostly continuous across the area, although not extremely dense; average LiDAR estimated canopy cover was $47 \%$ pre-fire and $30 \%$ post-fire. Two different agents of forest change had considerably altered forest structure in the area prior to the Pole Creek Fire. Mountain pine beetle impacted $58 \%$ of the area within the fire perimeter, while various types of forest harvest took place across 11\% of the fire area (McCarley, 2016). 


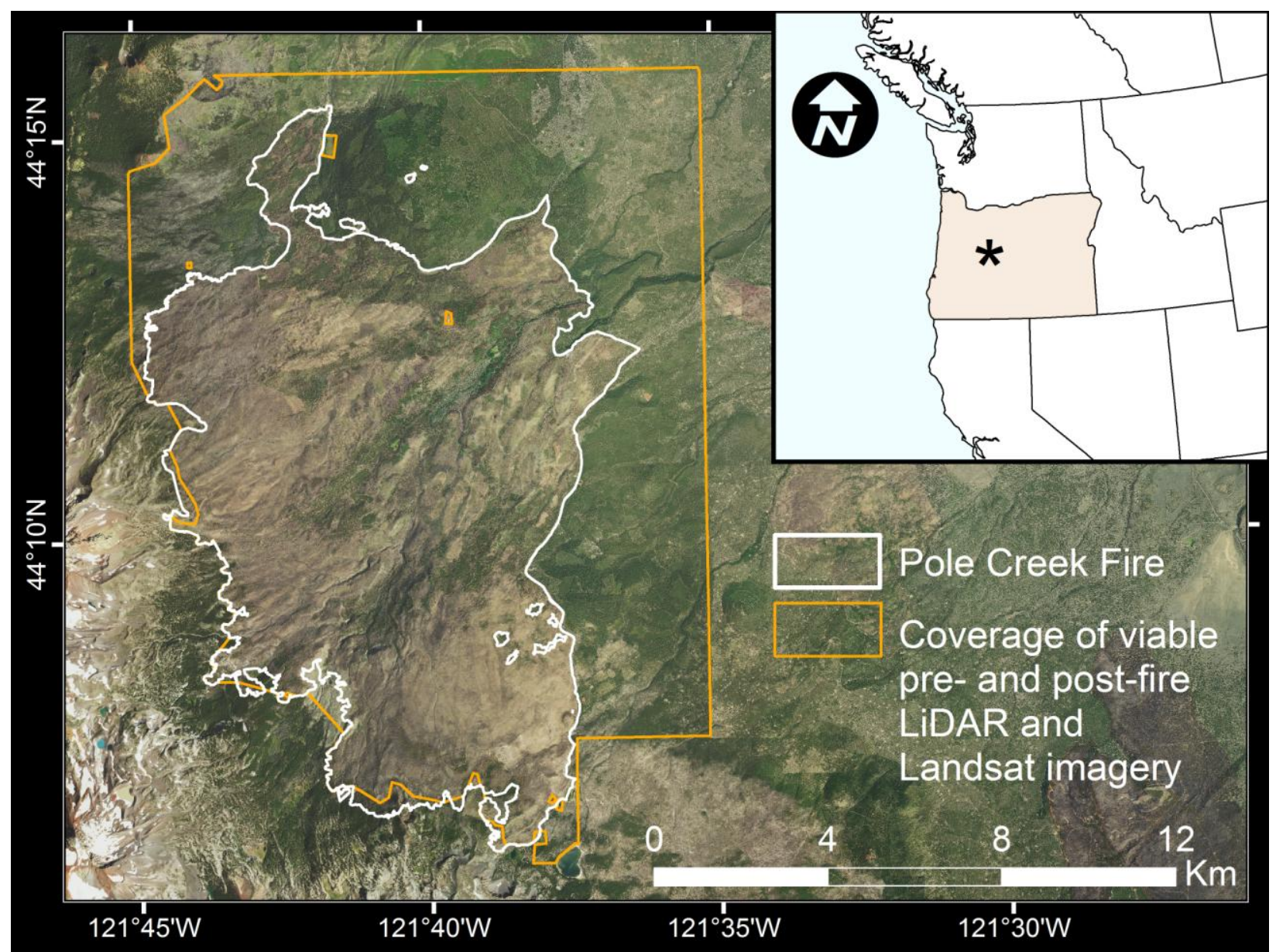

Figure 1. Location of Pole Creek Fire (white outline) in central Oregon and the overlap of viable LiDAR and Landsat imagery (orange outline with crosshatch). Data overlaid on 2014 National Agricultural Imagery Program (NAIP) imagery.

\subsection{Data pre-processing}

Pre- and post-fire USGS Level 1 terrain-corrected (L1T) Landsat Thematic Mapper (TM) and Operational Land Imager (OLI) scenes were selected (Table 1) to meet best practices for scene selection for fire effects analysis described by Key (2006). This includes identifying scenes with a minimal number of intervening years between pre- and post-fire acquisition dates to minimize non-fire induced change, comparable phenology, comparable sun angle to minimize shadowing, nonexistence of snow or cloud cover over the burn area, data completeness, and maximizing the number of pixels for analysis. Based on the criteria, scenes from the Landsat 
Enhanced Thematic Mapper-Plus (ETM+) were excluded because they reduced the number of useable pixels considerably. This eliminated scenes from 2012 and prompted the need to utilize two different sensors for the pre- and post-fire images. However, despite the differences in spectral channel and bit size between Landsat OLI and the two previous missions (Landsat TM and ETM+), prior work has indicated that once band brightness values are converted to top-ofatmosphere reflectance there is no discernable difference in spectral signature of burned surfaces (Koutsias \& Pleniou, 2015).

Remaining candidate scenes were evaluated for best match. All of the scene combinations had a few patches of snow at higher elevations, creating interference with change analysis. Therefore, pixels containing snow were excluded once the best phenological pair was determined. For similar reasons open water bodies with seasonally variable levels were also excluded, resulting in the omission of $1.6 \%$ of the pixels within the fire perimeter. In order to prepare and standardize Landsat scenes for multi-date comparison, band brightness values were transformed to top-of-atmosphere reflectance (Chander \& Markham, 2003), then atmospherically corrected to at-surface-reflectance using the Cos(t) model (Mahiny \& Turner, 2007) and Dark Object Subtraction (Chavez, 1996).

Discrete, multi-return LiDAR data were acquired pre- and post-fire by the same vendor (Table 1) at a survey altitude of 900 meters above ground level with a $28^{\circ}$ field of view $\left( \pm 14^{\circ}\right.$ from nadir) and at least 50\% side-lap following recommendations of forestry LiDAR acquisition parameters as highlighted by Evans et al. (2009). In each case, the vendor post-processed the LiDAR data in order to ensure geometric accuracy and develop a 1-meter digital terrain model. Following data delivery, the heights of the pre- and post-fire data were normalized by subtracting the terrain model from the LiDAR point cloud using the USDA Forest Service's FUSION 
software package (McGaughey, 2014). Pre-fire LiDAR data were re-projected using LAStools (Isenburg, 2013) from state plane into UTM to match the post-fire LiDAR and Landsat data.

Table 1: Data Acquisition Parameters

\begin{tabular}{|c|c|c|c|}
\hline & Date & Sensor Type & Resolution \\
\hline $\begin{array}{l}\text { Pre- Fire } \\
\text { LiDAR }\end{array}$ & $\begin{array}{c}\text { October 7-11, } \\
2009\end{array}$ & Leica ALS50 & Average 8 pulses $/ \mathrm{m}^{2}$ \\
\hline $\begin{array}{c}\text { Pre- Fire } \\
\text { Multi-spectral }^{\text {Image }^{\mathrm{a}}}\end{array}$ & July 23, 2011 & Landsat $5 \mathrm{TM}$ & $\begin{array}{l}\text { Bands } 1-5 \text { and } 7,30 \mathrm{~m} \\
\text { Band } 6 \text { (thermal), } 120 \mathrm{~m}\end{array}$ \\
\hline $\begin{array}{c}\text { Post- Fire } \\
\text { Multi-spectral }^{\text {Image }}\end{array}$ & June 10, 2013 & Landsat 8 OLI & $\begin{array}{l}\text { Bands } 1-7 \text { and } 9,30 \mathrm{~m} \\
\text { Bands } 10 \text { and } 11 \text { (thermal), } 100 \mathrm{~m} \\
\text { Band } 8 \text { (panchromatic), } 15 \mathrm{~m}\end{array}$ \\
\hline $\begin{array}{l}\text { Post-Fire } \\
\text { LiDAR }\end{array}$ & $\begin{array}{c}\text { October 8-11, } \\
2013\end{array}$ & Leica ALS50 & Average 8 pulses $/ \mathrm{m}^{2}$ \\
\hline
\end{tabular}

${ }^{\mathrm{a}}$ Scene located at Worldwide Reference System 2: Path 45, Row 29.

\subsection{Spectral indices}

Fifteen spectral indices were calculated based on the findings of other studies that sought to quantify fire effects through use of remote sensing data. Indices were calculated per equations provided in seminal papers (Table 2). Following practices by Key (2006) and Cansler \& McKenzie (2012), an offset value was applied that accounted for phenological differences between the pre- post-fire images by identifying homogenous reference forested areas outside of the fire perimeter and computing the mean value for each spectral index in those areas. Under the assumption that unchanged reference areas should have a differenced index value of zero, the entire scene was adjusted by adding or subtracting the value of the reference mean for each 
index. These indices, as well as individual Landsat reflectance bands, were used as predictor variables for LiDAR-derived structure metrics in the analysis. 
Table 2: Remotely Sensed Spectral Predictors

\begin{tabular}{|c|c|c|c|}
\hline Index Acronym & Change Spectral Index & Derivation & Key Reference \\
\hline $\begin{array}{l}\text { dB, dG, dR, dNIR, } \\
\text { dSWIR1, } \\
\text { dSWIR2 }\end{array}$ & $\begin{array}{l}\Delta \text { Landsat Bands (Blue, Green, Red, } \\
\text { Near Infrared, Shortwave } \\
\text { Infrared 1, and Shortwave } \\
\text { Infrared 2) }\end{array}$ & - & - \\
\hline dNBR & $\Delta$ Normalized Burn Ratio & $\left(\rho_{\mathrm{NIR}}-\rho_{\mathrm{SWIR} 2}\right) /\left(\rho_{\mathrm{NIR}}+\rho_{\mathrm{SWIR} 2}\right)$ & (Key \& Benson, 2006) \\
\hline RdNBR & Relative dNBR & $\mathrm{dNBR} / \sqrt{ }\left(\left|\mathrm{NBR}_{\mathrm{pre}}\right|\right) / 1000$ & (Miller \& Thode, 2007) \\
\hline dNDVI & $\begin{array}{l}\Delta \text { Normalized Differenced } \\
\text { Vegetation Index }\end{array}$ & $\left(\rho_{\mathrm{NIR}}-\rho_{\mathrm{r}}\right) /\left(\rho_{\mathrm{NIR}}+\rho_{\mathrm{r}}\right)$ & (Rouse et al., 1974) \\
\hline dMIRBI & $\Delta$ Mid-Infrared Bi-Spectral Index & $10 \rho_{\mathrm{SWIR} 2}-9.8 \rho_{\mathrm{SWIR} 1}+2.0$ & (Trigg \& Flasse, 2001) \\
\hline dCSI & $\Delta$ Char Soil Index & $\rho_{\mathrm{NIR}} / \rho_{\mathrm{SWIR} 1}$ & (Smith et al., 2007) \\
\hline dSAVI & $\Delta$ Soil Adjusted Vegetation Index & $\left(\rho_{\mathrm{NIR}}-\rho_{\mathrm{r}}\right)(1+\mathrm{L}) /\left(\rho_{\mathrm{SWIR} 1}\right)$ & (Huete, 1988) \\
\hline dTCB, dTCG, dTCW & $\begin{array}{l}\Delta \text { Tasseled Cap Brightness, } \\
\text { Greenness, and Wetness }\end{array}$ & $\begin{array}{c}\left(\rho_{\mathrm{b}}^{*} \varepsilon\right)+\left(\rho_{\mathrm{g}}^{*} \varepsilon\right)+\left(\rho_{\mathrm{r}}^{*} \varepsilon\right)+\left(\rho_{\mathrm{NIR}}{ }^{*} \varepsilon\right) \\
+\left(\rho_{\mathrm{SWIR} 1}{ }^{*} \varepsilon\right)+\left(\rho_{\mathrm{SWIR} 2}{ }^{*} \varepsilon\right)\end{array}$ & $\begin{array}{r}\text { (Crist, 1985; Kauth \& Thomas, } \\
1976)\end{array}$ \\
\hline dPC1, dPC2, dPC3 & $\begin{array}{l}\Delta \text { The first three Principle } \\
\text { Components }\end{array}$ & $\begin{array}{c}\left(\mathrm{dB}^{*} \alpha\right)+\left(\mathrm{dG}^{*} \alpha\right)+\left(\mathrm{dR}^{*} \alpha\right)+ \\
(\mathrm{dNIR} \alpha)+\left(\mathrm{dSWIR} 1^{*} \alpha\right)+ \\
\left(\mathrm{dSWIR} 2^{*} \alpha\right)\end{array}$ & (Patterson \& Yool, 1998) \\
\hline dDWI & $\begin{array}{l}\Delta \text { Normalized Differenced Water } \\
\text { Index }\end{array}$ & $\left(\rho_{\mathrm{NIR}}-\rho_{\mathrm{SWIR} 1}\right) /\left(\rho_{\mathrm{NIR}}+\rho_{\mathrm{SWIR} 1}\right)$ & $(\mathrm{Gao}, 1996)$ \\
\hline d74 & $\Delta$ Band $7 / 4$ Ratio & $\rho_{\text {SWIR } 2} / \rho_{\text {NIR }}$ & (Kushla \& Ripple, 1998) \\
\hline d75 & $\Delta$ Band $7 / 5$ Ratio & $\rho_{\text {SWIR } 2} / \rho_{\text {SWIR } 1}$ & (Epting et al., 2005) \\
\hline
\end{tabular}




\subsection{LiDAR metrics}

The metrics used in this study (Table 3) were selected based on use in other forestry applications (e.g., Hudak et al., 2012; Wing et al., 2012), comparability with fire-effects strata assessed in the widely-used CBI (Key \& Benson, 2006), and theoretical sensitivity to fire effects. Based on the recommended definition of surface fuel by Brown et al. (1982), a 1.8 meter threshold was used for calculating canopy cover (above $1.8 \mathrm{~m}$ ) and mean surface fuel height (below 1.8m).

The LiDAR metrics were generated by first binning the pre- and post-fire height normalized LiDAR point clouds into 30-meter voxels that spatially matched the Landsat pixel data (Figure 2). Using FUSION, select statistics for each 30-meter voxel cell were calculated and converted into individual rasters. Given small vertical errors in the surface model and subsequent normalized LiDAR cloud (Tinkham et al., 2012), only returns above 0.15 meters were used such that primarily vegetative changes would be measured. From the resulting rasters, both absolute change (pre - post) and relative change ((pre - post)/pre) were calculated to generate the LiDAR metrics used in analysis. 


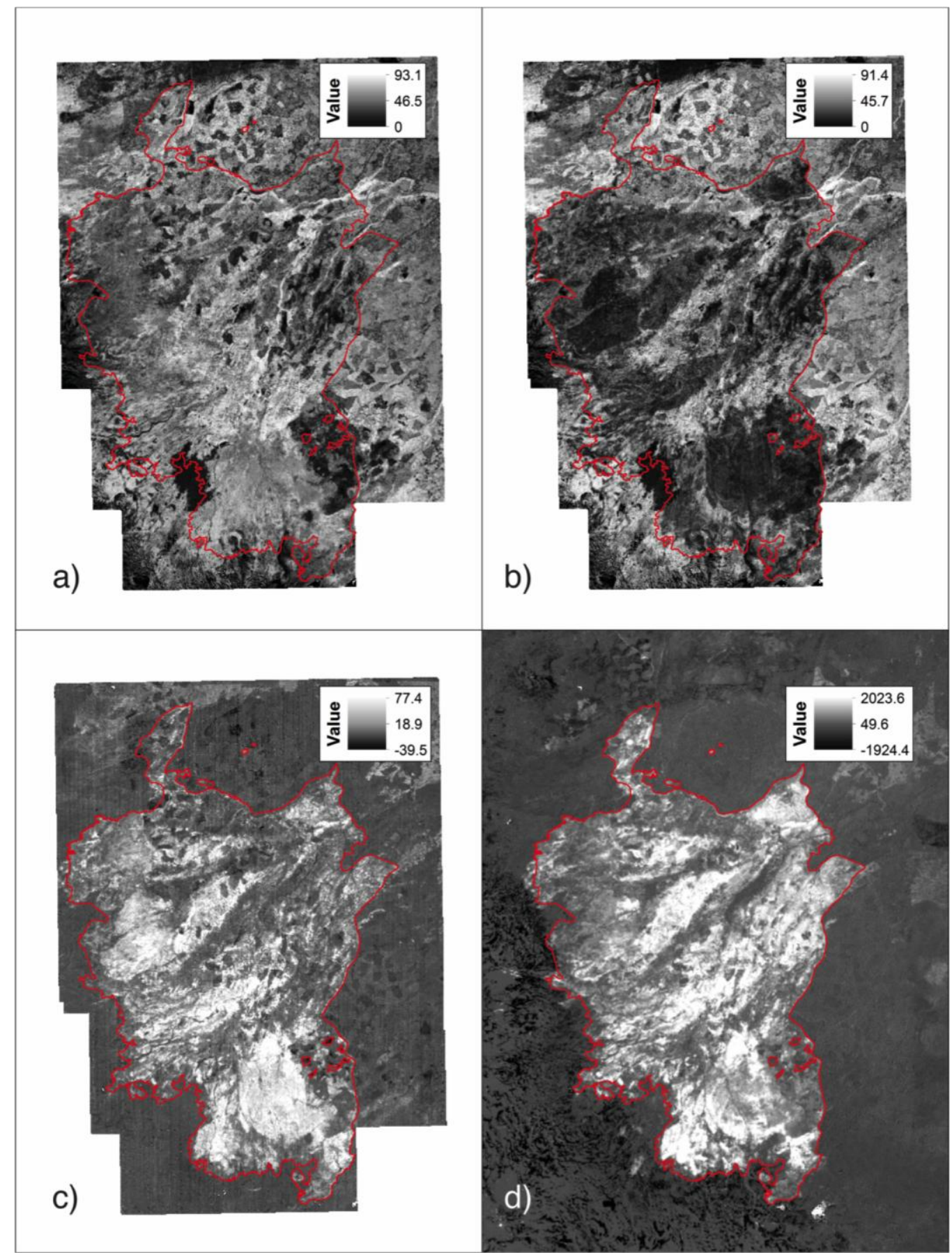

Figure 2. LiDAR-derived (a) pre-fire canopy cover (\%CC), (b) post-fire canopy cover (\%CC), (c) change in canopy cover estimated by LiDAR $(\Delta \% \mathrm{CC})$, and (d) the delta normalized burn ratio index (dNBR). Fire perimeter shown in red. 
Table 3: LiDAR Metrics of Forest Structure

\begin{tabular}{|c|c|c|}
\hline Metric Acronym & LiDAR Metric & Interpretation \\
\hline $\begin{array}{l}\text { dMHT } \\
\text { dSD } \\
\text { dSKW } \\
\text { dS1 } \\
\text { dS2 } \\
\text { dS3 } \\
\text { dS4 } \\
\text { dS5 } \\
\text { dMSFH } \\
\text { dCC } \\
\text { dCRR } \\
\text { dCD }\end{array}$ & $\begin{array}{l}\text { Mean of returns } \quad \text { pre - post } \\
\text { Standard deviation of returns } \\
\text { Skewness value of returns } \\
\text { Percent of returns }<1 \mathrm{~m} \\
\text { Percent of returns } \geq 1 \mathrm{~m} \text { and } \leq 5 \mathrm{~m} \\
\text { Percent of returns }>5 \mathrm{~m} \text { and } \leq 8 \mathrm{~m} \\
\text { Percent of returns }>8 \mathrm{~m} \text { and } \leq 20 \mathrm{~m} \\
\text { Percent of returns }>20 \mathrm{~m} \\
\text { Mean height of returns } \leq 1.8 \mathrm{~m} \\
\text { Percent of returns }>1.8 \mathrm{~m} \\
\text { Using vegetation heights: (mean }- \text { min }) /(\max -\min ) \\
\text { Mean vegetation height } * \text { canopy cover }\end{array}$ & $\begin{array}{l}\Delta \text { Mean vegetation height } \\
\Delta \text { Vegetation height standard deviation } \\
\Delta \text { Vegetation height skewness } \\
\Delta \text { Percent returns in } 1^{\text {st }} \text { strata } \\
\Delta \text { Percent returns in } 2^{\text {nd }} \text { strata } \\
\Delta \text { Percent returns in } 3^{\text {rd }} \text { strata } \\
\Delta \text { Percent returns in } 4^{\text {th }} \text { strata } \\
\Delta \text { Percent returns in } 5^{\text {th }} \text { strata } \\
\Delta \text { Mean surface fuel height } \\
\Delta \text { Percent Canopy Cover } \\
\Delta \text { Canopy Relief Ratio } \\
\Delta \text { Canopy Density }\end{array}$ \\
\hline $\begin{array}{l}\text { RdMHT } \\
\text { RdSD } \\
\text { RdSKW } \\
\text { RdS1 } \\
\text { RdS2 } \\
\text { RdS3 } \\
\text { RdS4 } \\
\text { RdS5 } \\
\text { RdMSFH } \\
\text { RdCC } \\
\text { RdCRR } \\
\text { RdCD }\end{array}$ & $\begin{array}{l}\text { Mean of returns } \\
\text { Standard deviation of returns } \\
\text { Skewness value of returns } \\
\text { Percent of returns }<1 \mathrm{~m} \\
\text { Percent of returns } \geq 1 \mathrm{~m} \text { and } \leq 5 \mathrm{~m} \\
\text { Percent of returns }>5 \mathrm{~m} \text { and } \leq 8 \mathrm{~m} \\
\text { Percent of returns }>8 \mathrm{~m} \text { and } \leq 20 \mathrm{~m} \\
\text { Percent of returns }>20 \mathrm{~m} \\
\text { Mean height of returns } \leq 1.8 \mathrm{~m} \\
\text { Percent of returns }>1.8 \mathrm{~m} \\
\text { Using vegetation heights: (mean }- \text { min }) /(\max -\min ) \\
\text { Mean vegetation height } * \text { canopy cover }\end{array}$ & $\begin{array}{l}\text { Relative } \Delta \text { Mean vegetation height } \\
\text { Relative } \Delta \text { Vegetation height standard deviation } \\
\text { Relative } \Delta \text { Vegetation height skewness } \\
\text { Relative } \Delta \text { Percent returns in } 1^{\text {st }} \text { strata } \\
\text { Relative } \Delta \text { Percent returns in } 2^{\text {nd }} \text { strata } \\
\text { Relative } \Delta \text { Percent returns in } 3^{\text {rd }} \text { strata } \\
\text { Relative } \Delta \text { Percent returns in } 4^{\text {th }} \text { strata } \\
\text { Relative } \Delta \text { Percent returns in } 5^{\text {th }} \text { strata } \\
\text { Relative } \Delta \text { Mean surface fuel height } \\
\text { Relative } \Delta \text { Percent Canopy Cover } \\
\text { Relative } \Delta \text { Canopy Relief Ratio } \\
\text { Relative } \Delta \text { Canopy Density }\end{array}$ \\
\hline
\end{tabular}




\subsection{Analysis}

To quantify relationships between LiDAR-derived metrics of forest structural change and spectral indices commonly used to quantify burn severity, a preliminary screening was first conducted. A Pearson's correlation coefficient was calculated for all combination pairs of differenced spectral indices and differenced LiDAR metrics in order to eliminate redundancy and insignificant models. Poorly correlated pairs (less than an absolute value of 0.5) were eliminated from further evaluation. The remaining pairs were assessed using pairwise ordinary least squares (OLS) regressions and comparing their $\mathrm{r}^{2}$ values. All statistics were computed in the software $\mathrm{R}$ (R Development Core Team, 2014).

To assess model consistency across bark beetle impacts and forest harvest areas, the fire area was stratified into three classes: pixels impacted by bark beetles pre-fire (MPB), pixels impacted by forest harvest pre-fire (MGMT), and pixels with no pre-fire impacts (Fire; McCarley, 2016). OLS regression models were calculated predicting LiDAR-inferred change in canopy cover (dCC) from d74, dNBR, RdNBR for each stratified class and a class of all pixels (Universal), resulting in four regression models for each spectral index. Each of the four models was then applied to all four classes of pixels (MPB, MGMT, Fire-only, All) to determine how accurately any given model could predict $\mathrm{dCC}$ within a class of pixels. Accuracy was quantified by calculating the root mean square error (RMSE) for each model-class combination between actual change in percent canopy cover $(\Delta \% \mathrm{CC})$ from $\mathrm{dCC}$ and $\Delta \% \mathrm{CC}$ predicted by the model.

While some studies have sought to improve model predictions of burn severity through inclusion of environmental data at mismatched spatial scales (e.g., Birch et al., 2015; Dillon et al., 2011; Kane et al., 2015), simultaneous autoregressive modeling, a form of spatially weighted regression, has been shown to improve on non-spatially explicit regression models (Cressie, 
1993; Haining, 1990; Lewis et al., 2011). Simultaneous autoregression incorporates the spatial autocorrelation in burn pattern, providing a proxy for other influential variables (i.e., geomorphic or climatic process) not included in the model (Kissling \& Carl, 2007; Prichard \& Kennedy, 2014; Wimberly et al., 2009). Therefore, this study hypothesized that using a spatially explicit model would improve the relationship between LiDAR metrics and spectral indices.

To test this hypothesis, the outputs of spatial and non-spatial models were compared. The simultaneous autoregression produces a Nagelkerke pseudo-r ${ }^{2}$ (Nagelkerke, 1991), which is not directly comparable to an OLS $\mathrm{r}^{2}$. Like $\mathrm{r}^{2}$, the pseudo-r ${ }^{2}$ ranges from a low of zero to a high of one, so a higher pseudo- $r^{2}$ will reflect a better prediction, making the pseudo- $\mathrm{r}^{2}$ value is an acceptable method to compare the relationships between spectral indices and LiDAR metrics. However, while $r^{2}$ is a measure of variation explained by the model, Nagelkerke pseudo- $r^{2}$ describes the improvement of the fitted model over the null model. Pseudo-r ${ }^{2}$ values are more difficult to interpret because they cannot be similarly interpreted between data sets. Therefore, AIC was used to assess model improvement. The simultaneous autoregressive model was applied in R using the 'spdep' package (Bivand, 2002), following the equation:

$$
\mathrm{Y}=\mathrm{X} \beta+\lambda \mathrm{W}(\mathrm{Y}-\mathrm{X} \beta)+\varepsilon
$$

where $\mathrm{Y}$ is the dependent variable, $\mathrm{X}$ is the explanatory variable, $\beta$ is the vector of coefficients, $\lambda$ is the autoregressive coefficient, $\mathrm{W}$ is the row-standardized matrix of spatial weights, and $\varepsilon$ is the uncorrelated error term (Cressie, 1993; Haining, 1990). The spatial weights matrix was defined to give weight to pixels within a pre-defined neighborhood based on the inverse of the distance from focal center to the center of neighboring pixels. These values were then row-standardized, giving the neighboring pixels a total summed weight of one, and all other pixels a weight of zero. Following the recommendation of Kissling \& Carl (2007) and practice of other wildfire studies 
incorporating simultaneous autoregression (Meigs et al. 2016; Prichard \& Kennedy, 2014), neighborhood pixels were defined as those centered within 60 meters because it minimized Akaike's Information Criterion (AIC; Akaike, 1974) and residual spatial autocorrelation over other possible neighborhood distances explored. Due to the large number of observations, a Chebyshev sparse matrix approach was applied that estimates the autoregressive coefficient rather than calculating it directly from eigenvalues (Pace \& LeSage, 2004). This method allowed us to apply the model to a much larger area than would be computationally possible otherwise, avoiding having to subsample the data as others have (Lewis et al., 2011; Wimberly et al., 2009).

\section{Results}

The $\mathrm{r}^{2}$ values for the 63 viable OLS regression models were plotted in a matrix to examine the magnitude and quality of the relationships between spectral indices and LiDAR metrics (Figure 3; Table S2). The best-observed relationship was between d74 and change in canopy cover $\left(\mathrm{dCC} ; \mathrm{r}^{2}=0.63\right)$, followed by $\mathrm{d} 75$ and dCC $\left(\mathrm{r}^{2}=0.62\right)$, dSWIR2 and dCC $\left(\mathrm{r}^{2}=\right.$ $0.52)$, and dMIRBI and relative change in canopy cover $(\mathrm{RdCC})\left(\mathrm{r}^{2}=0.52\right)$. OLS regression models utilizing dCC produced the highest $\mathrm{r}^{2}$ values (or only $\mathrm{r}^{2}$ whereas other LiDAR metrics did not pass preliminary screening) for 11 of the 15 spectral indices (dSWIR2, dNBR, dNDVI, dTCW, dPC1, d74, d75, dB, dG, dSAVI, and dNDWI indices). The surface and understory metrics, including those describing surface fuel height (dMSFH, RdMSFH) and the lower-to-mid strata of the forest (dS2, dS3, RdS2), modeled poorly relative to the upper strata and canopy metrics, and $\mathrm{r}^{2}$ values decreased closer to the surface. The highest $\mathrm{r}^{2}$ found for the subcanopy metrics was between the change in percent returns from 5-8 meters (dS3) and d75 $\left(r^{2}=0.41\right)$, 
while the highest $r^{2}$ found for surface metrics was between the relative change in mean surface fuel height $($ RdMSFH $)$ and both dNDVI and $d 74\left(r^{2}=0.28\right)$. The worst $r^{2}$ value for a model not eliminated was between dPC1 and relative change in percent returns 1-5 meters (RdS2; $\mathrm{r}^{2}=$ 0.25). All models were statistically significant $(\mathrm{p}<0.0001)$, even poorly performing ones, due to the extremely large sample size $(n=117,520)$.

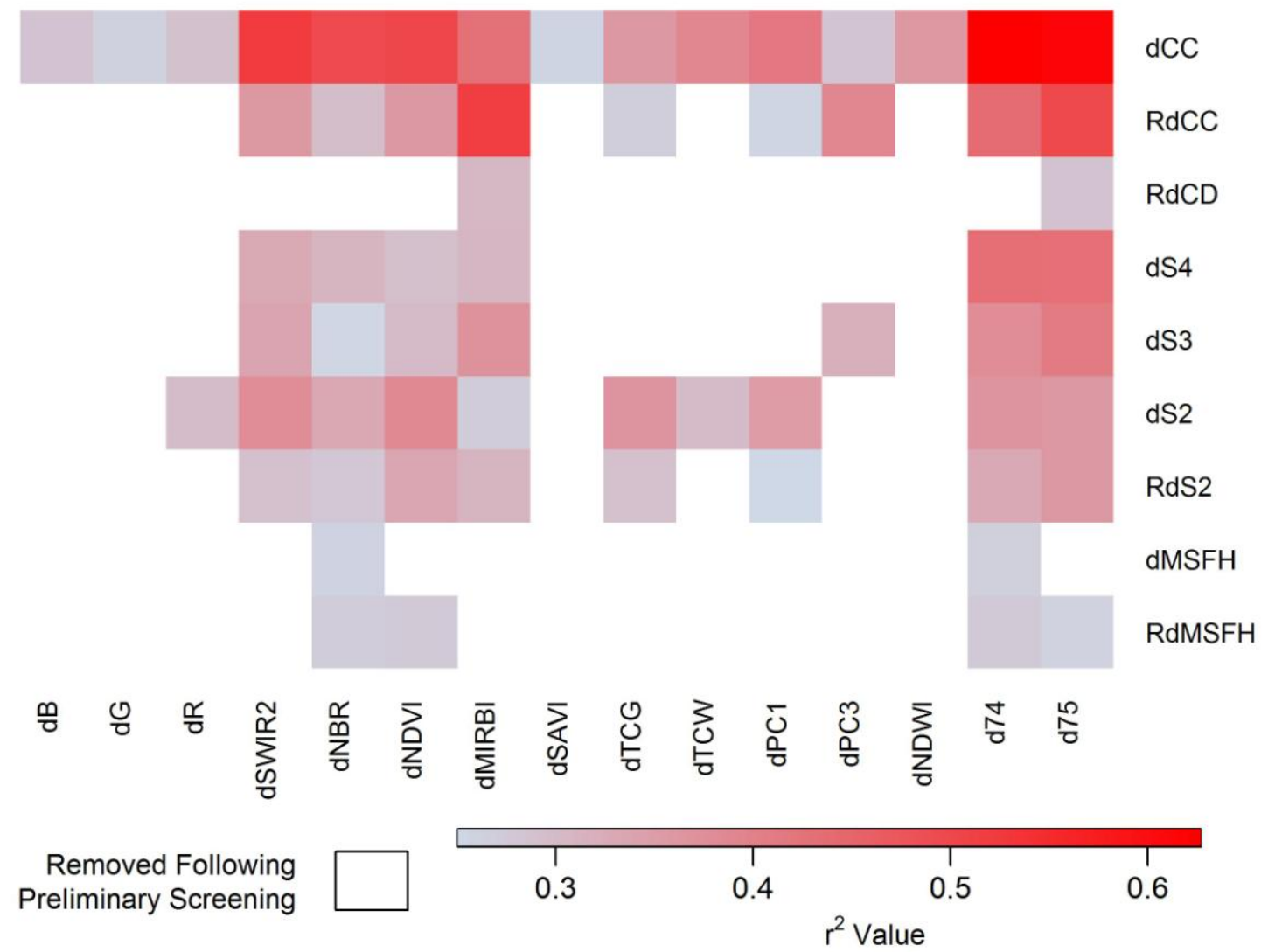

Figure 3. Comparison of $r^{2}$ values for pairwise ordinary least squares (OLS) regression between LiDAR metrics and spectral indices; models with a Pearson's Correlation below an absolute value of 0.5 omitted (preliminary screening); $\mathrm{dS} 2$, delta percent returns tall shrubs and trees 1-5 $\mathrm{m}$; dS3, delta percent returns tall shrubs / intermediate trees; dS4, delta percent returns intermediate trees / upper canopy; dMSFH, delta mean surface fuel height; dCC, delta canopy cover; RdS2, relative delta percent returns tall shrubs and trees 1-5 m; RdMSFH, relative delta mean surface fuel height; RdCC, relative delta canopy cover; RdCD, relative delta canopy density; $\mathrm{dB}$, delta blue; $\mathrm{dG}$, delta green; $\mathrm{dR}$, delta red; dSWIR2, delta shortwave infrared 2; dNBR, delta normalized burn ratio; dNDVI, delta normalized differenced vegetation index; dMIRBI, mid-Infrared bi-spectral index; dSAVI, delta soil adjusted vegetation index; dTCG, 
delta tasseled cap greenness; dTCW, delta tasseled cap wetness; dPC1, delta principle component 1; dPC3, delta principle component 3; dNDWI, delta normalized differenced wetness index; $\mathrm{d} 74$, delta band 7/4 ratio; $\mathrm{d} 75$, delta band 7/5 ratio.

In general, all models produced lower RMSE when applied to the source class of pixels as opposed to other pixel classes (Figure 4). The highest RMSE corresponded to models utilizing RdNBR for MPB pixels using models developed in Fire $(22.1 \Delta \% \mathrm{CC})$ or MGMT $(19.3 \Delta \% \mathrm{CC})$ source pixels. RMSE differences between the three spectral indices were smallest when the models developed in fire pixels and MGMT pixels were applied to MGMT pixels. The largest discrepancy between indices was for the model developed in fire pixels applied to all pixels or MPB pixels. In this case, RdNBR performed significantly worse $(17.8 \Delta \% \mathrm{CC}$ and $22.1 \Delta \% \mathrm{CC})$ than the dNBR $(11.0 \Delta \% \mathrm{CC}$ and $12.4 \Delta \% \mathrm{CC})$ and $\mathrm{d} 74(9.0 \Delta \% \mathrm{CC}$ and $9.3 \Delta \% \mathrm{CC})$. The Universal model utilizing $\mathrm{d} 74$ for all pixels had the lowest $\mathrm{RMSE}(8.4 \Delta \% \mathrm{CC}$ and $8.5 \Delta \% \mathrm{CC})$ when applied to the MPB and Fire pixel classes, and the highest RMSE $(12.3 \Delta \% \mathrm{CC})$ when applied to the MGMT class. Consistently for all spectral indices, the MGMT model yielded the highest RMSE values when applied to the non-MGMT classes (Fire, MPB, and All pixels). 


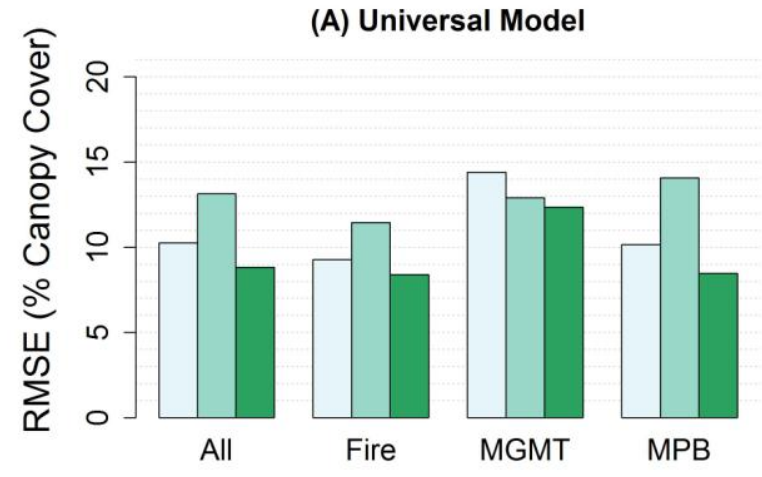

(C) MGMT Model
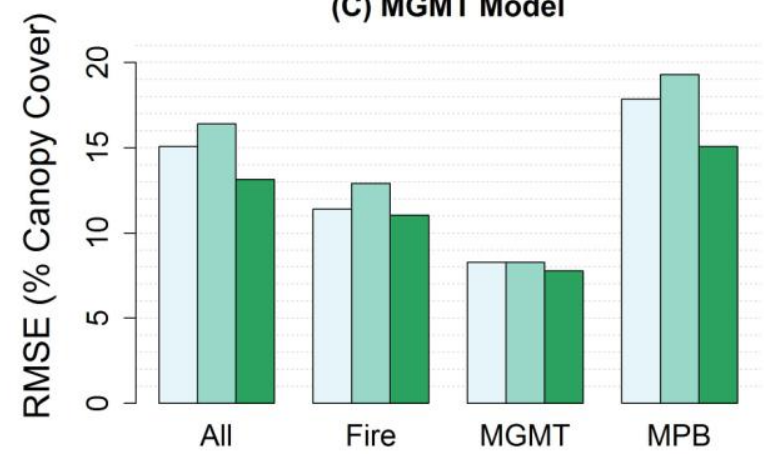

(B) Fire Model

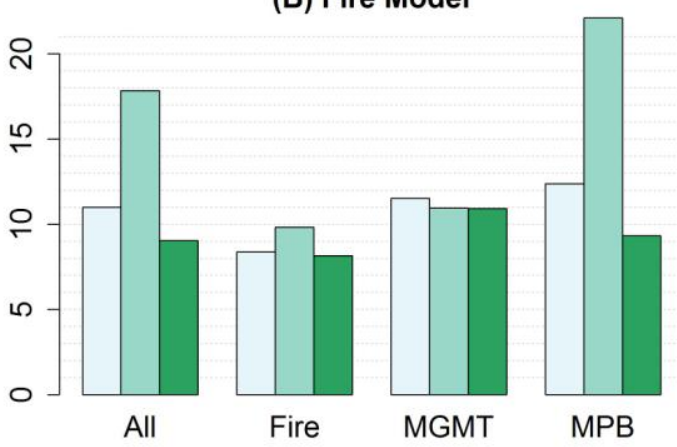

(D) MPB Model

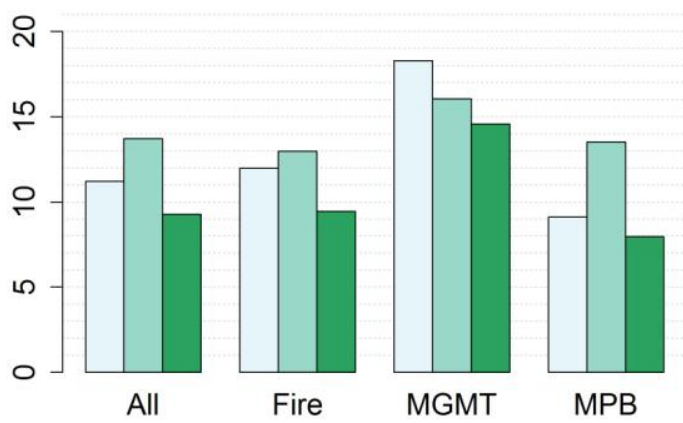

Figure 4. Root mean squared error (RMSE) percentages for the application of regression models to classes of pixels for four different pixels class groups: All pixels within the burned area (Universal model), Fire-only pixels (Fire), pixels affected by Forest timber management pre-fire (MGMT), and pixels affected by mountain pine beetle pre-fire (MPB). Each regression model (panels a through d) predicts the change in percent canopy cover (dCC) for each of the four classes of pixels (x-axis groupings in each panel) from three spectral indices: the delta Normalized Burn Ratio (dNBR), Relative dNBR (RdNBR), and the delta band 7/5 ratio (d75).

Pseudo- $r^{2}$ values were generated using simultaneous autoregression and plotted for each of the model pairs (Figure 5; Table S3). With spatial autocorrelation accounting for the influence of unknown predictor variables, the best-observed relationship was still between $\mathrm{d} 74$ and dCC (pseudo-r ${ }^{2}=0.86$ ), followed by dNBR and dCC $\left(\right.$ psuedo- $\left.\mathrm{r}^{2}=0.85\right)$, dNDVI and dCC (pseudo-r ${ }^{2}$ $=0.84)$. Change in canopy cover $(\mathrm{dCC})$ was the best predicted LiDAR metrics for all spectral indices (pseudo-r ${ }^{2}$ ranging from 0.79 to 0.86 ; Figure 5), followed by change in percent returns 8- 
20 meters (dS4), RdCC, and change in percent returns 5-8 meters (dS3). RdS2 uniformly had the weakest association to all spectral indices (pseudo-r ${ }^{2}$ ranging from 0.45 to 0.47 ). All of the spatial models were also statistically significant $(\mathrm{p}<0.0001)$. The AIC values were compared for the spatially explicit and OLS models for each of the 63 viable pairs (Figure 6; Table S4). For all pairs the AIC value was lower using simultaneous autoregression, indicating model improvement (Figure 7). The biggest decrease in AIC was observed for dSAVI and dCC, while the smallest was between $\mathrm{d} 75$ and RdS2. Across spectral indices, dCC and dS4 saw the greatest improvement from simultaneous autoregression.

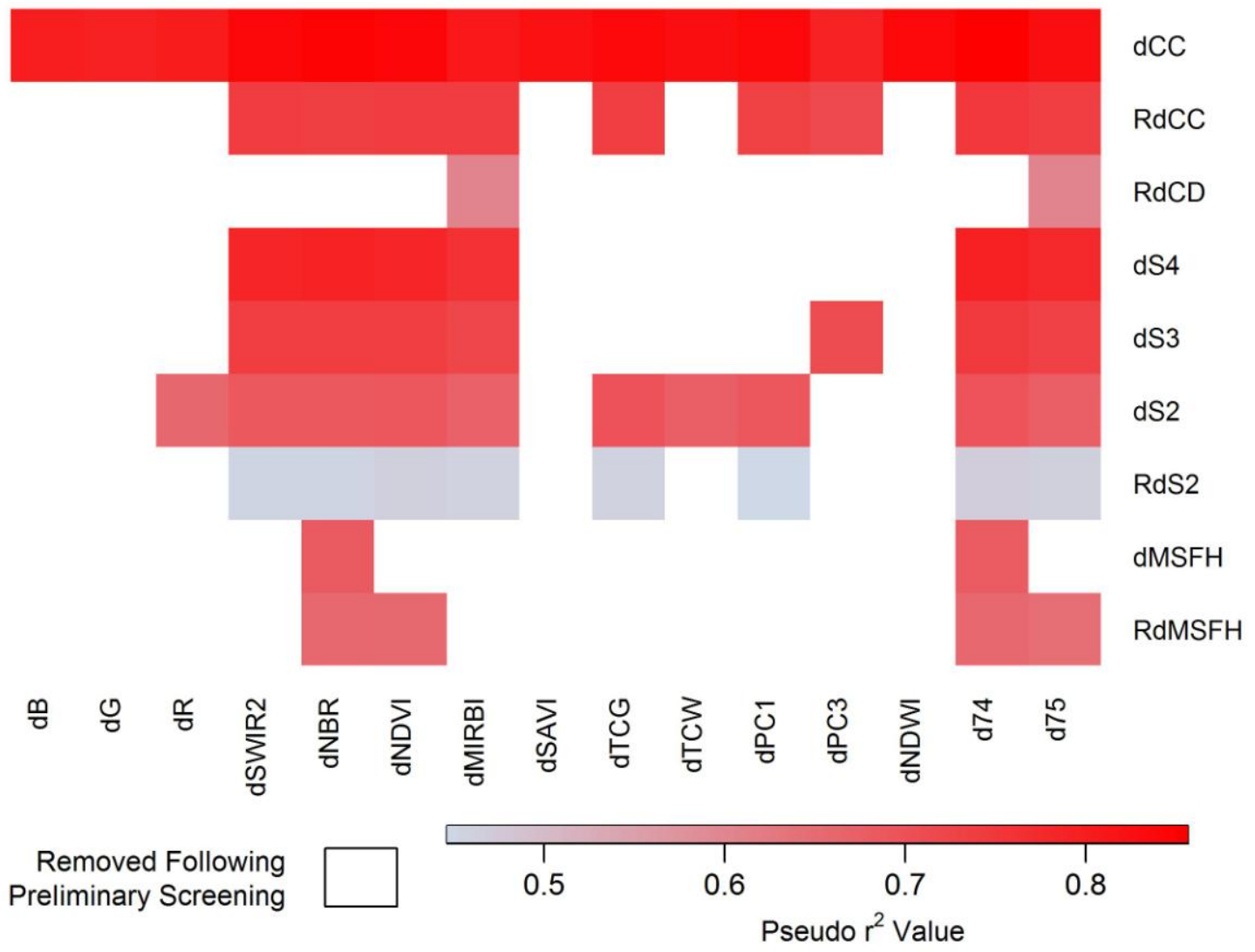

Figure 5. Comparison of pseudo-r ${ }^{2}$ values for simultaneous autoregressive modelling between LiDAR metrics and spectral indices; models with a Pearson's Correlation below an absolute value of 0.5 omitted (preliminary screening); dS2, delta percent returns tall shrubs and trees 1-5 $\mathrm{m}$; dS3, delta percent returns tall shrubs / intermediate trees; dS4, delta percent returns 
intermediate trees / upper canopy; dMSFH, delta mean surface fuel height; dCC, delta canopy cover; RdS2, relative delta percent returns tall shrubs and trees 1-5 m; RdMSFH, relative delta mean surface fuel height; RdCC, relative delta canopy cover; RdCD, relative delta canopy density; $\mathrm{dB}$, delta blue; $\mathrm{dG}$, delta green; $\mathrm{dR}$, delta red; dSWIR2, delta shortwave infrared 2; dNBR, delta normalized burn ratio; dNDVI, delta normalized differenced vegetation index; dMIRBI, mid-Infrared bi-spectral index; dSAVI, delta soil adjusted vegetation index; dTCG, delta tasseled cap greenness; dTCW, delta tasseled cap wetness; dPC1, delta principle component 1 ; dPC 3 , delta principle component 3 ; dNDWI, delta normalized differenced wetness index; $\mathrm{d} 74$, delta band 7/4 ratio; $\mathrm{d} 75$, delta band $7 / 5$ ratio.
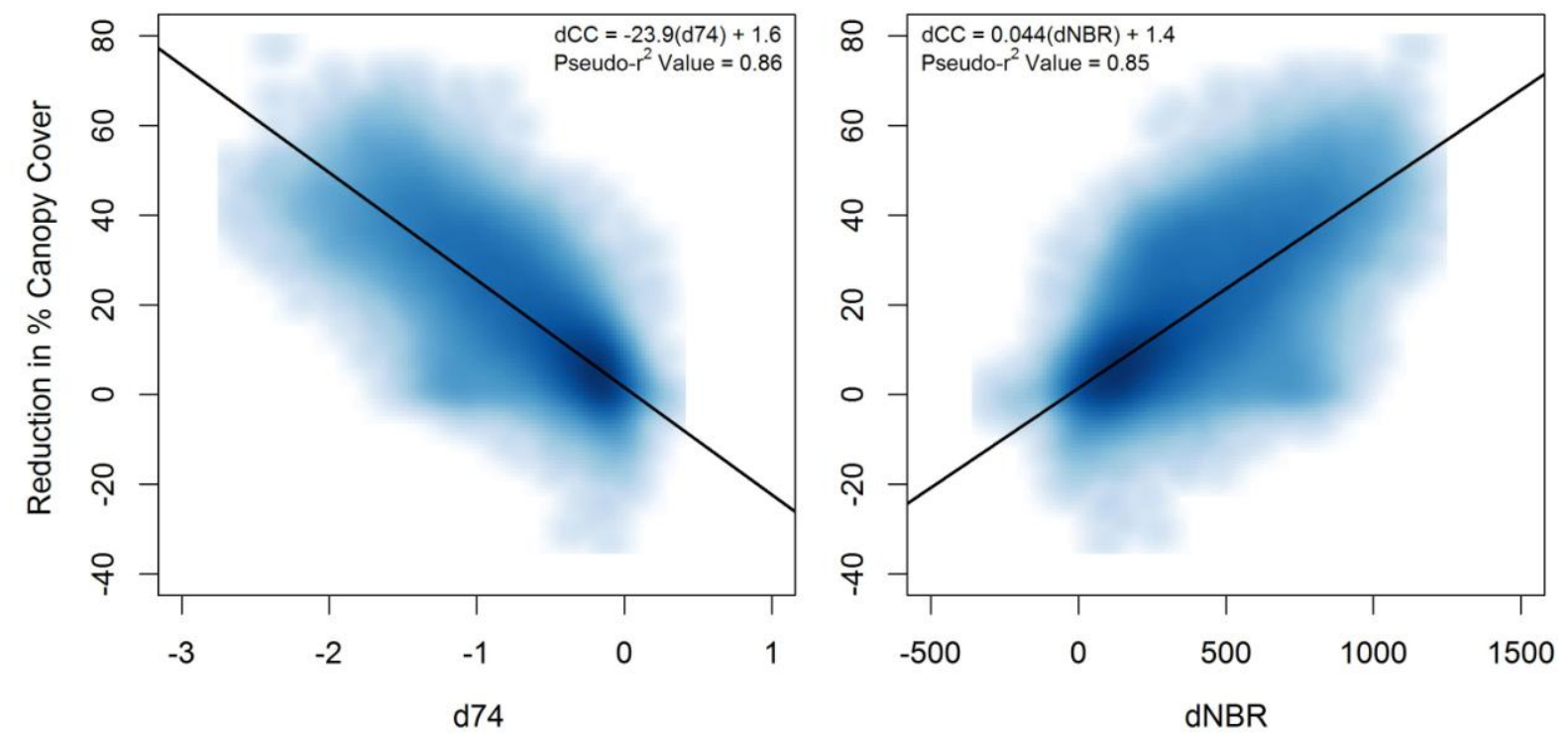

Figure 6. Density scatterplots (blue) for the two best relationships observed using the simultaneous autoregression model (black line). Spectral indices used were the delta band 7/4 ratio (d74) and delta normalized burn ratio (dNBR). Both were used to predict change in canopy cover (dCC). 


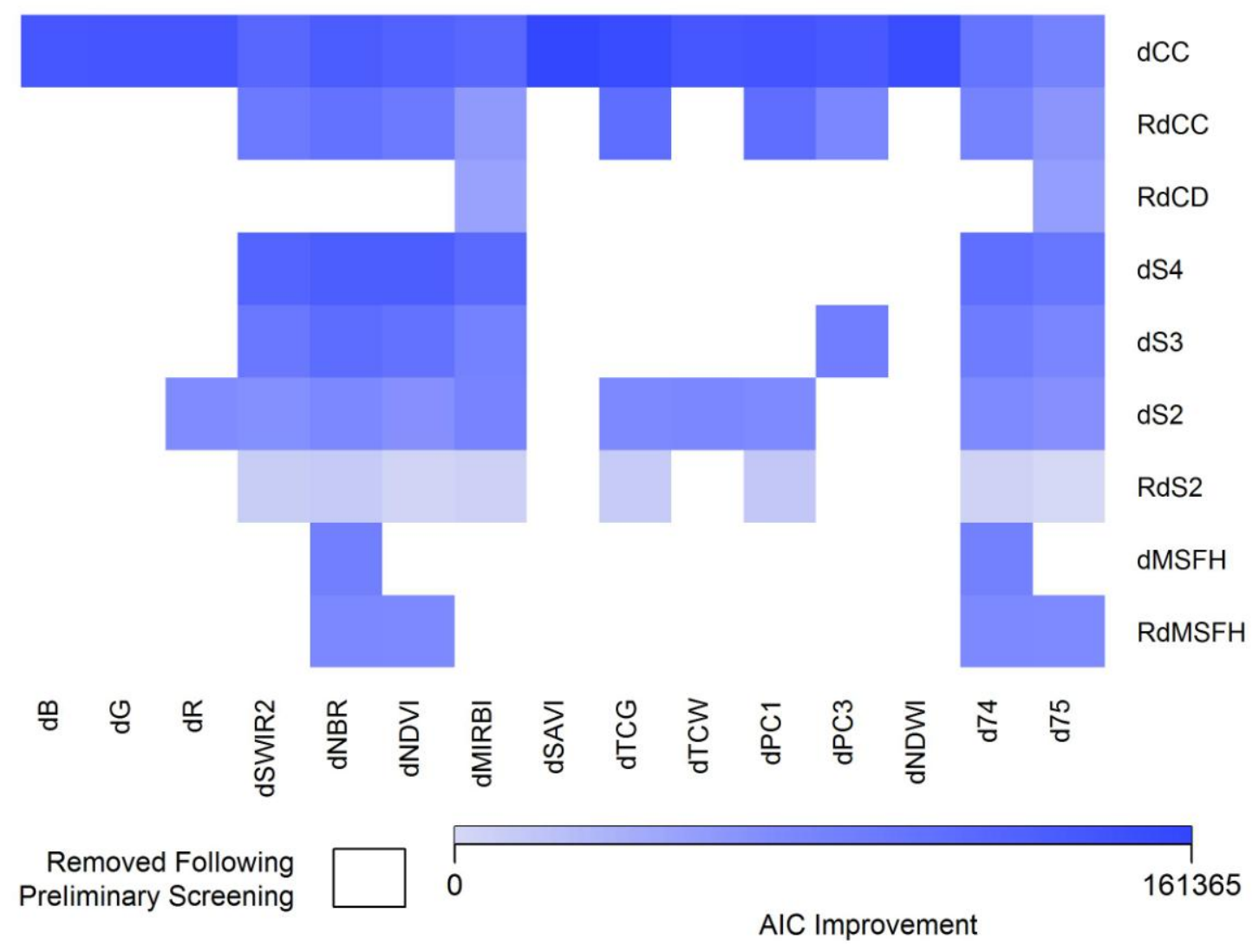

Figure 7. Improvement over ordinary least squares (OLS) models through the use of simultaneous autoregressive (SAR) modelling measured by difference in Akaike information criterion (AIC) values (positive indicates improvement, zero no change, and negative suggests worsening); models with a Pearson's Correlation below an absolute value of 0.5 omitted (preliminary screening); dS2, delta percent returns tall shrubs and trees 1-5 m; dS3, delta percent returns tall shrubs / intermediate trees; dS4, delta percent returns intermediate trees / upper canopy; dMSFH, delta mean surface fuel height; dCC, delta canopy cover; RdS2, relative delta percent returns tall shrubs and trees 1-5 m; RdMSFH, relative delta mean surface fuel height; $\mathrm{RdCC}$, relative delta canopy cover; RdCD, relative delta canopy density; dB, delta blue; dG, delta green; dR, delta red; dSWIR2, delta shortwave infrared 2; dNBR, delta normalized burn ratio; dNDVI, delta normalized differenced vegetation index; dMIRBI, mid-Infrared bi-spectral index; dSAVI, delta soil adjusted vegetation index; dTCG, delta tasseled cap greenness; dTCW, delta tasseled cap wetness; dPC1, delta principle component 1; dPC3, delta principle component 3; dNDWI, delta normalized differenced wetness index; d74, delta band 7/4 ratio; d75, delta band $7 / 5$ ratio. 


\section{Discussion}

\subsection{Regression Relationships}

LiDAR-inferred change in canopy cover $(\mathrm{dCC})$ was the biophysical fire effect most accurately predicted from spectral remote sensing from the LiDAR metrics and spectral indices evaluated. The dCC was most accurately predicted by indices that contrasted the short-wave infrared band (SWIR2) with the near-infrared (NIR), including the delta 7/4 band ratio and the dNBR. Neither of these results is particularly novel, rather, they validate across an entire fire the relationships that have been demonstrated for only small sets of field plots that are almost never randomly sampled due to the challenges of randomly locating plots in complex and often hazardous post-fire terrain (Key \& Benson, 2006).

Relationships with spectra improved closer to the top of the canopy; other than absolute and relative changes in canopy cover, the best correlated LiDAR metrics were for change in percent returns for 5-8 meters (dS3) and 8-20 meters (dS4). The model improvements observed with increasing height strata highlight the difficulty of measuring reflectance values anywhere but the top-most-surface, and validate previous reports that spectral remote sensing is not fully able to detect changes in the understory (Hudak et al., 2007; Kolden, Lutz, Key, Kane, \& van Wagtendonk, 2012; Wulder et al., 2009). The exception to this trend was the poor relationship observed between change in percent returns above 20 meters (dS5) and the spectral indices. While $73 \%$ of pixels had pre- and post- fire LiDAR returns above 20 meters, they were usually few in number, having a median value of only $3-4 \%$ of all returns in the pixels having returns in that stratum. The weak relationships between dS5 or RdS5 and all of the spectral indices potentially result from the lack of vegetation in most areas across that stratum (largely treetops). 
SWIR2 wavelengths demonstrated the strongest relationship to structural change. Change in canopy cover $(\mathrm{dCC})$ was only weakly correlated to $\mathrm{dB}, \mathrm{dG}$, and $\mathrm{dR}$. A stronger relationship with dNIR or $\mathrm{dR}$ and $\mathrm{dCC}$ was expected given the sensitivity of these bands to fire-induced changes in vegetation (Chuvieco et al., 2002; Rogan \& Yool, 2001). However, the poor relationship with dNIR is consistent with Smith et al. (2009), who demonstrated that near infrared reflectance was insensitive to mean LiDAR plot height. It is also explained by the inclusion of both non-photosynthetic vegetation (including both branches and dead or scorched needles) and live, photosynthetic vegetation in the canopy cover metric in this dataset. While return intensity values can be used to discriminate between live and dead trees in order to more accurately quantify change in live canopy, the pre-fire LiDAR data did not include the aircraft trajectory files needed to normalize intensity values in order to make pre-fire and post-fire intensities comparable (Bright et al., 2013).

Although a strong correlation to dNIR or dR was not observed, dNDVI was a relatively good indicator of LiDAR-derived metrics, particularly change in canopy cover. This may suggest that the proportion of dead trees with needles still on providing error in the canopy cover metric was not signifcant. Using simultaneous autoregression, the indices that had the best relationship to dCC were $\mathrm{d} 74$ and dNBR, both of which use the SWIR2 and NIR bands. The individual SWIR2 band was observed to have a strong relationship with dCC, while dNIR was a strong predictor only when used in combination with other bands (i.e., d74, dNBR, dNDVI). Many other studies have indicated that SWIR2 and NIR provide the best correlation with field measurements incorporating fire effects on all strata (Key \& Benson, 2006; Miller \& Yool, 2002; van Wagtendonk et al., 2004; White et al., 1996). Based on the findings in this study, SWIR2 appears to be the most sensitive band for detecting fire-induced changes for canopy cover. 
These results present further evidence to support the position that it may be inappropriate to use spectral indices that have only been validated for comprehensive estimates of burn severity in limited ecosystems as proxies for specific burn severity biometrics at regional to global scales (Kolden et al., 2015; Lentile et al., 2006; Smith et al., 2016b). Specifically, the results presented here suggest that the "validation" of spectral indices with comprehensive field measures such as the Composite Burn Index is particularly problematic, particularly as canopy cover increases, as the spectral signal is primarily sensitive to the top of the canopy and not very sensitive to the understory. Chuvieco et al. (2006) described this strata mixing problem and the use of radiative transfer models (RTMs) as an alternative. However, subsequent results further testing RTMs for this purpose (De Santis \& Chuvieco, 2007; Disney et al., 2011) have been largely ignored in the subsequent literature that continues to focus on correlating CBI to spectral reflectance as "validation" of certain burn severity spectral indices. This is particularly true in the United States, where these correlations are meant to justify the use of dNBR and RdNBR burn severity products (e.g., MTBS) for a range of applications based on these validations, despite increasing evidence that alternative spectral indices such as dNDVI or dPRI (photochemical reflectance index; Gamon, 1992) are more strongly responsive to specific ecophysiology traits, such as responses in net primary productivity and plant mortality (e.g., Sparks et al., 2016; Smith et al., 2016b).

\subsection{Model consistency across agents of change}

Model accuracy was inconsistent across stratified pre-fire agents of change, including pre-fire Management (MGMT) and Mountain Pine Beetle (MPB), with two implications. First, the considerably greater errors associated with applying models derived from MGMT and MPB 
pixel classes suggest that these pre-fire agents of change may considerably alter the predicted fire impacts in this ecosystem. This concern is specifically directed at canopy cover, as that is the forest structure metric the spectral indices most strongly predicted. For MPB, this is not surprising given that there is minimal pre-fire canopy cover across highly affected areas.

Second, it is evident that sampling bias can occur when pre-fire agents of change impact a large area of the fire but are not accounted for in the sampling design. While there is widespread acceptance of sampling stratification in fire ecology and applied ecological remote sensing more broadly, stratification often focuses on dominant vegetation types, or levels of wildfire burn severity (Key \& Benson, 2006; Hudak et al., 2007; Lentile et al., 2009). The models developed across all pixels (the Universal model) and from Fire only pixels yielded the most consistent error across pixels classes, while the models developed from MGMT and MPB pixels only performed well for that class of pixels and not the other classes. This suggests that if a universal model is to be applied to such analyses, sampling should be stratified appropriately to minimize model error, or separate models should be developed for specific groups of pixels.

\subsection{Simultaneous autoregressive model}

All models were improved by the use of simultaneous autoregression, supporting its previously stated value for landscape assessment of fire effects (Meigs et al., 2016; Prichard \& Kennedy, 2014; Wimberly et al., 2009). The greatest improvement in AIC was observed for change in canopy cover (dCC), which was already the best-predicted structural change measure. Prior attempts to model burn severity across landscapes have found topography to be among the strongest predictors of burn severity (Birch et al., 2015; Dillon et al., 2011; Kane et al., 2015). However, these studies note the limitations of trying to model burn severity at 30-meter spatial 
resolution utilizing predictor variables that are either only available at coarser spatial resolutions, such as climate and weather, or are modeled products that contain error, such as vegetation. This suggests that a simultaneous autoregressive model approach may provide the best proxy for specific biophysical measures of change (i.e., change in canopy cover), as it allows for consideration of additional explanatory environmental variables known to contribute to fire behavior (e.g., climate, topography, and vegetation) without requiring that these variables be included in the models (Kissling \& Carl, 2007), as data for these variables are often found at spatial scales much lower in resolution than fire effects data.

\subsection{Management Implications: $d N B R$ and RdNBR}

The dNBR and RdNBR spectral indices are widely applied within the United States and are the primary spectral indices within the MTBS project (Eidenshink et al., 2007). In addition, studies have been applying this methodology more broadly including research in Canada (Soverel et al., 2010) and Greece (Veraverbeke et al., 2010). Given the widespread use in the US and adoption as the primary spectral indices for the MTBS project, a discussion of dNBR and RdNBR performance as predictors of fire effects is warranted. In this study, dNBR outperformed RdNBR across all structural metrics. This was foremost the result of two distinctly different relationships observed between RdNBR and the LiDAR metrics, which was not observed for dNBR (Figure 8), and do not fit a linear or non-linear model. Further investigation revealed that in areas where pre-fire NBR was near zero and post-fire NBR was negative, the RdNBR equation produced unreasonably high values outside the expected range of -2000 to 2000 (Miller $\&$ Thode, 2007); McCarley (2016) determined that nearly all of these pixels (96\%) were in areas affected by pre-fire mountain pine beetle mortality. These results contradict studies that suggest 
RdNBR would perform better in forests where pre-fire disturbance has resulted in low-density vegetation cover (Miller \& Thode, 2007). They also raise questions regarding recent studies that have assessed the impact of mountain pine beetle outbreaks on subsequent fire severity where RdNBR was used as a proxy for burn severity (Meigs et al., 2016; Prichard \& Kennedy, 2014). (Parks et al. (2014) have highlighted this problem with RdNBR, and proposed the Relativized Burn Ratio (RBR) to address it. However, the RBR is neither widely utilized, nor does it follow best practices for development of new spectral indices to assess fire effects (Roy et al., 2006; Trigg \& Flasse, 2001). Consequently, it was not assessed here. 

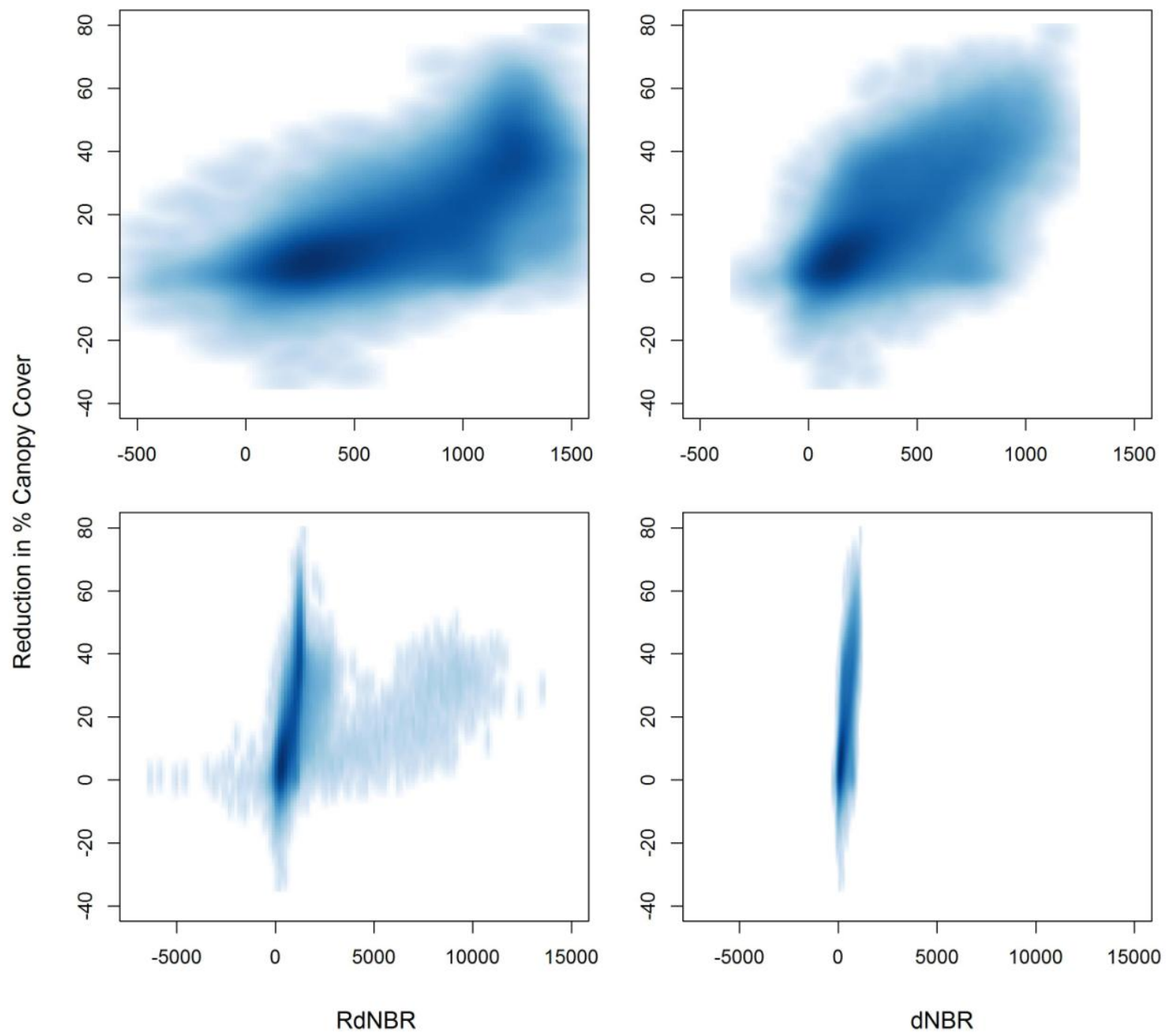

Figure 8. Relative delta Normalized Burn Ratio (RdNBR; left) and dNBR (right) versus and change in percent canopy cover estimated by LiDAR, plotted for comparison at different $\mathrm{x}$-axis ranges to show a separate trend occurring at high RdNBR values, but not for dNBR: -500 to 1500 (top) and -5000 to 15000 (bottom).

The poor performance of RdNBR in areas impacted by pre-fire MPB mortality and prefire forest management and harvest (MGMT) is further illuminated in the assessment of model consistency (Figure 4). As RdNBR was initially found to be a poor predictor of change in canopy cover $(\mathrm{dCC})$ in the preliminary screening, it is not surprising that the RMSE values for the RdNBR models were higher than observed for $\mathrm{d} 74$ or dNBR models. What is particularly 
notable, however, is that the Fire-only RdNBR model applied to the group of pixels affected prefire by MPB produces the highest RMSE (22.1 $\Delta \% \mathrm{CC})$ across the entire consistency assessment. This suggests that RdNBR performs very poorly when used to assess fire effects in MPBaffected forests. This agrees with Parks et al. (2014), who tested their proposed RBR index against dNBR and RdNBR for several fires and found that all indices (but particularly RdNBR) demonstrated the lowest correlations to field CBI for the 2006 Tripod Fire in Washington State, where nearly one-third of the fire area experience extensive MPB-induced tree mortality prior to the fire (Hicke et al., 2015).

\subsection{Future work}

One obvious limitation is that this study was conducted on a single fire that burned primarily in lodgepole pine and mixed conifer forest, thus additional work may be necessary to develop a robust model that can be used in different forest types. Nonetheless, the primary objective was not to establish a universal model between spectral remote sensing and structural change, but rather to validate the utility of Landsat spectral change indices by exploiting the opportunity afforded in the availability of overlapping pre- and post-fire LiDAR acquisitions for this fire. LiDAR provides a physical measure of vegetation structure and change that can be binned at a resolution commensurate with Landsat. The relationships that were observed suggest that further study is warranted in other vegetation types, but as acquisition of LiDAR data increases, it is likely that more paired pre- and post-fire datasets will become available to replicate the validation of Landsat sensor-derived spectral indices of fire effects. The need to define ecosystem-specific models that predict specific fire-induced forest structural change metrics at regionally significant scales is documented (Kolden et al., 2015), but as long as 
LiDAR remains cost-prohibitive, a robust spectral proxy derived from freely available Landsat data can provide effective measures of biophysical change that managers and scientists need.

In this study, the change in all LiDAR points was analyzed, regardless of other attributes. However, recently other studies have introduced the possibility of separating live and dead LiDAR returns using intensity values (Casas et al., 2016; Kim et al., 2009; Wing et al., 2015). This discrimination may enhance future models since refining $\mathrm{dCC}$ specifically to change in live canopy cover would likely produce stronger correlations to spectral change in the NIR. As noted above, this study was not able to discriminate between live and dead returns due a lack of the necessary information to normalize return intensity values for the pre-fire acquisition.

LiDAR also offers the opportunity to derive useful data such as biomass, basal area, or leaf area index in places where field calibration sites are available (Hudak et al., 2009; Lefsky et al., 2002). The relationship between spectral data and these measurements may offer insights that structural metrics cannot. Given the importance of accurately modeling carbon emissions, LiDAR derived measures of change in biomass may prove particularly critical in continuing to evaluate the ability for spectral remote sensing to measure emissions and be scalable regionally and globally.

Finally, the issues that were observed with RdNBR in areas experiencing pre-fire mountain pine beetle mortality suggest a need to explore the effect of pre-fire disturbance on the ability to accurately model fire effects across a mosaic of forest history. While numerous studies have examined the relationship between mountain pine beetle and burn severity (e.g., Agne et al., 2016; Harvey et al., 2014; Meigs et al., 2016), none have addressed this issue at the landscape scale using measures of severity other than reflectance. The availability of pre- and 
post-fire LiDAR presents a rare opportunity to understand the effect of mountain pine beetle on subsequent structural change cause by wildfire.

\section{Conclusions}

This work addresses a critical gap in understanding the relationship between biophysical fire effects and spectral remote sensing by using multi-temporal LiDAR across an entire fire to measure fire-induced change in forest structure. By using LiDAR, the study overcame the primary difficulty with comparing multi-temporal spectral data to field measurements: the lack of pre-fire field observations. In this analysis, it was demonstrated that certain spectral indices, most notably d74 and dNBR, accurately detected change in canopy cover. There was not significant evidence for accurate detection of structural change in lower forest strata, suggesting that spectral remote sensing is primarily limited to detecting fire-induced changes in the topmost-surface. This finding is significant given the current use of reflectance data to evaluate post-fire habitat, secondary fire effects (i.e., flooding and erosion), comprehensive severity ratings, and carbon emissions. Additionally, model errors were inconsistent across pre-fire agents of change, demonstrating both the power of sampling bias to skew results and the limitations of spectral indices designated for burn severity to maintain accuracy when pre-fire agents of forest change such as bark beetles and timber management are present. Finally, integrating spatial autocorrelation into models improved accuracy, demonstrating that this approach may be superior to attempts to use environmental data at mismatched spatial scales for fire effects models. As LiDAR coverage increases spatially and temporally, there will be opportunities to further explore relationships between reflectance-based spectral indices and structural measures of change derived from LiDAR with high confidence at a commensurate scale. 


\section{Acknowledgements}

The authors are grateful for valuable feedback from the editor and anonymous external reviewers. This work was partially funded by the US Forest Service under Joint Venture Agreement 13-JV-11261900-072, and by the Department of the Interior Northwest Climate Science Center through Cooperative Agreement G14AP00177 from the United States Geological Survey (USGS). Its contents are solely the responsibility of the authors and do not necessarily represent the views of the NW CSC or the USGS. This manuscript is submitted for publication with the understanding that the United States Government is authorized to reproduce and distribute reprints for Governmental purposes.

\section{References Cited}

Abatzoglou, J. T., \& Williams, A. P. (2016). Impact of anthropogenic climate change on wildfire across western US forests. Proceedings of the National Academy of Sciences, 113, 1177011775. doi: 10.1073/pnas. 1607171113.

Agne, M. C., Woolley, T., \& Fitzgerald, S. (2016). Fire severity and cumulative disturbance effects in the post-mountain pine beetle lodgepole pine forests of the Pole Creek Fire. Forest Ecology and Management, 366, 73-86. http://doi.org/10.1016/j.foreco.2016.02.004

Akaike, H. (1974). A new look at the statistical model identification. IEEE Transactions on Automatic Control, 19(6), 716-723. http://doi.org/10.1109/TAC.1974.1100705

Andersen, H.-E., McGaughey, R. J., \& Reutebuch, S. E. (2005). Estimating forest canopy fuel parameters using LIDAR data. Remote Sensing of Environment, 94(4), 441-449. http://doi.org/10.1016/j.rse.2004.10.013

Barbero, R., Abatzoglou, J. T., Larkin, N. K., Kolden, C. A., \& Stocks, B. (2015). Climate change presents increased potential for very large fires in the contiguous United States. International Journal of Wildland Fire, 24(7), 892-899. http://doi.org/10.1071/WF15083

Bater, C. W., Wulder, M. A., White, J. C., \& Coops, N. C. (2010). Integration of LiDAR and digital aerial imagery for detailed estimates of lodgepole pine (Pinus contorta) volume killed by mountain pine beetle (Dendroctonus ponderosae). Journal of Forestry, 108(3), 111-119.

Birch, D. S., Morgan, P., Kolden, C. A., Abatzoglou, J. T., Dillon, G. K., Hudak, A. T., \& Smith, A. M. S. (2015). Vegetation, topography and daily weather influenced burn severity in central Idaho and western Montana forests. Ecosphere, 6(1), 1-23. 
http://doi.org/10.1890/ES14-00213.1

Bishop, B. D., Dietterick, B. C., White, R. A., \& Mastin, T. B. (2014). Classification of plotlevel fire-caused tree mortality in a redwood forest using digital orthophotography and LiDAR. Remote Sensing, 6(3), 1954-1972. http://doi.org/10.3390/rs6031954

Bivand, R. (2002). Spatial econometrics functions in R: Classes and methods. Journal of Geographical Systems, 4(4), 405-421. http://doi.org/10.1007/s101090300096

Bright, B. C., Hicke, J. A., \& Hudak, A. T. (2012). Estimating aboveground carbon stocks of a forest affected by mountain pine beetle in Idaho using lidar and multispectral imagery. Remote Sensing of Environment, 124, 270-281. http://doi.org/10.1016/j.rse.2012.05.016

Bright, B. C., Hudak, A. T., McGaughey, R., Andersen, H. E., \& Negrón, J. (2013). Predicting live and dead tree basal area of bark beetle affected forests from discrete-return lidar. Canadian Journal of Remote Sensing, 39(sup1), S99-S111.

Brown, J. K., Oberhau, R. D., \& Johnston, C. M. (1982). Handbook for Inventorying surface fuels and biomass in the Interior West. General Technical Report INT-129. Ogden, UT: USDA Forest Service, Intermountain Forest and Range Experiment Station (48 pp.).

Cansler, C. A., \& McKenzie, D. (2012). How robust are burn severity indices when applied in a new region? Evaluation of alternate field-based and remote-sensing methods. Remote Sensing, 4(2), 456-483. http://doi.org/10.3390/rs4020456

Cansler, C. A., \& Mckenzie, D. (2014). Climate, fire size, and biophysical setting control fire severity and spatial pattern in the northern Cascade Range, USA. Ecological Applications, 24(5), 1037-1056. http://doi.org/10.1890/13-1077.1

Casas, Á., García, M., Siegel, R. B., Koltunov, A., Ramírez, C., \& Ustin, S. (2016). Burned forest characterization at single-tree level with airborne laser scanning for assessing wildlife habitat. Remote Sensing of Environment, 175, 231-241. http://doi.org/10.1016/j.rse.2015.12.044

Chander, G., \& Markham, B. (2003). Revised Landsat-5 TM Radiometrie Calibration Procedures and Postcalibration Dynamic Ranges. IEEE Transactions on Geoscience and Remote Sensing, 41(11), 2674-2677. http://doi.org/10.1109/TGRS.2003.818464

Chavez, P. S. J. (1996). Image-based atmospheric corrections- revisited and improved. Photogrammetric Engineering and Remote Sensing, 62(9), 1025-1035. http://doi.org/00991112/96/6209-1025

Chuvieco, E., Martín, M. P., \& Palacios, A. (2002). Assessment of different spectral indices in the red-near-infrared spectral domain for burned land discrimination. International Journal of Remote Sensing, 23(23), 5103-5110. http://doi.org/10.1080/01431160210153129

Chuvieco, E., Riaño, D., Danson, F. M., \& Martin, P. (2006). Use of a radiative transfer model to simulate the postfire spectral response to burn severity. Journal of Geophysical Research: Biogeosciences, 111(G4), n/a-n/a. http://doi.org/10.1029/2005JG000143

Cocke, A. E., Fulé, P. Z., \& Crouse, J. E. (2005). Comparison of burn severity assessments using Differenced Normalized Burn Ratio and ground data. International Journal of Wildland Fire, 14(2), 189. http://doi.org/10.1071/WF04010

Cressie, N. (1993). Statistics for Spatial Data. New York: Wiley.

Crist, E. P. (1985). A TM Tasseled Cap equivalent transformation for reflectance factor data. Remote Sensing of Environment, 17(3), 301-306. http://doi.org/10.1016/00344257(85)90102-6

De Santis, A., \& Chuvieco, E. (2007). Burn severity estimation from remotely sensed data: 
Performance of simulation versus empirical models. Remote Sensing of Environment, 108(4), 422-435. http://doi.org/10.1016/j.rse.2006.11.022

De Santis, A., Chuvieco, E., \& Vaughan, P. J. (2009). Short-term assessment of burn severity using the inversion of PROSPECT and GeoSail models. Remote Sensing of Environment, 113(1), 126-136. http://doi.org/10.1016/j.rse.2008.08.008

Dillon, G. K., Holden, Z. A., Morgan, P., Crimmins, M. A., Heyerdahl, E. K., \& Luce, C. H. (2011). Both topography and climate affected forest and woodland burn severity in two regions of the western US, 1984 to 2006. Ecosphere, 2(12), 1-33. http://doi.org/10.1890/ES11-00271.1

Disney, M. I., Lewis, P., Gomez-Dans, J., Roy, D. P., Wooster, M. J., \& Lajas, D. (2011). 3D radiative transfer modelling of fire impacts on a two-layer savanna system. Remote Sensing of Environment, 115(8), 1866-1881. http://doi.org/10.1016/j.rse.2011.03.010

Eidenshink, J., Schwind, B., Brewer, K., Zhu, Z., Quayle, B., \& Howard, S. (2007). A Project for Monitoring Trends in Burn Severity. Fire Ecology Special Issue, 3(1), 3-21.

Epting, J., Verbyla, D., \& Sorbel, B. (2005). Evaluation of remotely sensed indices for assessing burn severity in interior Alaska using Landsat TM and ETM+. Remote Sensing of Environment, 96(3-4), 328-339. http://doi.org/10.1016/j.rse.2005.03.002

Evans, J. S., Hudak, A. T., Faux, R., \& Smith, A. M. S. (2009). Discrete return lidar in natural resources: Recommendations for project planning, data processing, and deliverables. Remote Sensing, 1(4), 776-794. http://doi.org/10.3390/rs1040776

Gamon, J. Peñuelas, J., Field, C. (1992). A narrow-waveband spectral index that tracks diurnal changes in photosynthetic efficiency. Remote Sensing of Environment, 41, 35-44.

Gao, B. C. (1996). NDWI - A normalized difference water index for remote sensing of vegetation liquid water from space. Remote Sensing of Environment, 58(3), 257-266. http://doi.org/10.1016/S0034-4257(96)00067-3

García, M., Riaño, D., Chuvieco, E., \& Danson, F. M. (2010). Estimating biomass carbon stocks for a Mediterranean forest in central Spain using LiDAR height and intensity data. Remote Sensing of Environment, 114(4), 816-830. http://doi.org/10.1016/j.rse.2009.11.021

García, M., Riaño, D., Chuvieco, E., Salas, J., \& Danson, F. M. (2011). Multispectral and LiDAR data fusion for fuel type mapping using Support Vector Machine and decision rules. Remote Sensing of Environment, 115(6), 1369-1379. http://doi.org/10.1016/j.rse.2011.01.017

Gillespie, A. J. R. (1999). Rationale for a National Annual Forest Inventory Program. Journal of Forestry, 97(12), 16-20.

Haining, R. (1990). Spatial data analysis in the social and environmental sciences. Cambridge: Cambridge University Press. http://doi.org/10.1017/CBO9780511623356

Harvey, B. J., Donato, D. C., \& Turner, M. G. (2014). Recent mountain pine beetle outbreaks, wildfire severity, and postfire tree regeneration in the US Northern Rockies. Proceedings of the National Academy of Sciences, 111(42). http://doi.org/10.1073/pnas.1411346111

Hessburg, P. F., Churchill, D. J., Larson, A. J., Haugo, R. D., Miller, C., Spies, T. A., ... Reeves, G. H. (2015). Restoring fire-prone Inland Pacific landscapes: seven core principles. Landscape Ecology, 30(10), 1805-1835. http://doi.org/10.1007/s10980-015-0218-0

Hicke, J. A., Meddens, A. J. H., \& Kolden, C. A. (2015). Recent Tree Mortality in the Western United States from Bark Beetles and Forest Fires. Forest Science, 62, 1-13.

Hudak, A. T., Evans, J. S., \& Smith, A. M. S. (2009). LiDAR utility for natural resource 
managers. Remote Sensing, 1(4), 934-951. http://doi.org/10.3390/rs1040934

Hudak, A. T., Morgan, P., Bobbitt, M. J., Smith, A. M. S., Lewis, S. A., Lentile, L. B., ... McKinley, R. A. (2007). The Relationship of Multispectral Satellite Imagery to Immediate Fire Effects. Fire Ecology, 3(1), 64-90. http://doi.org/10.4996/fireecology.0301064

Hudak, A. T., Strand, E. K., Vierling, L. A., Byrne, J. C., Eitel, J. U. H., Martinuzzi, S., \& Falkowski, M. J. (2012). Quantifying aboveground forest carbon pools and fluxes from repeat LiDAR surveys. Remote Sensing of Environment, 123, 25-40. http://doi.org/10.1016/j.rse.2012.02.023

Huete, A. R. (1988). A soil-adjusted vegetation index (SAVI). Remote Sensing of Environment, 25(3), 295-309. http://doi.org/10.1016/0034-4257(88)90106-X

Isenburg, M. (2013). LAStools - Efficient tools for LiDAR processing. Retrieved from http://lastools.org

Kane, V. R., Lutz, J. A., Alina Cansler, C., Povak, N. A., Churchill, D. J., Smith, D. F., ... North, M. P. (2015). Water balance and topography predict fire and forest structure patterns. Forest Ecology and Management, 338, 1-13. http://doi.org/10.1016/j.foreco.2014.10.038

Kane, V. R., Lutz, J. A., Roberts, S. L., Smith, D. F., McGaughey, R. J., Povak, N. A., \& Brooks, M. L. (2013). Landscape-scale effects of fire severity on mixed-conifer and red fir forest structure in Yosemite National Park. Forest Ecology and Management, 287, 17-31. http://doi.org/10.1016/j.foreco.2012.08.044

Kane, V. R., North, M. P., Lutz, J. A., Churchill, D. J., Roberts, S. L., Smith, D. F., ... Brooks, M. L. (2014). Assessing fire effects on forest spatial structure using a fusion of Landsat and airborne LiDAR data in Yosemite National Park. Remote Sensing of Environment, 151, 89101. http://doi.org/10.1016/j.rse.2013.07.041

Kauth, R. J., \& Thomas, G. S. (1976). The tasselled cap - A graphic description of the spectraltemporal development of agricultural crops as seen by Landsat. In Final Proceedings: 2 nd International Symposium on Machine Processing of Remotely Sensed Data. West Lafayette, IN: Purdue University.

Keeley, J. E. (2009). Fire intensity, fire severity and burn severity: a brief review and suggested usage. International Journal of Wildland Fire, 18(1), 116. http://doi.org/10.1071/WF07049

Key, C. H. (2006). Ecological and Sampling Constraints on Defining Landscape Fire Severity. Fire Ecology, 2(2), 34-59. http://doi.org/10.4996/fireecology.0202034

Key, C. H., \& Benson, N. C. (2006). Landscape Assessment (LA): Sampling and Analysis Methods. In D. C. Lutes, R. E. Keane, J. F. Caratti, C. H. Key, N. C. Benson, S. Sutherland, \& L. J. Gangi (Eds.), FIREMON: Fire effects monitoring and inventory system (p. 51). Fort Collins, CO: USDA Forest Service General Technical Report. RMRS-GTR-164-CD.

Kim, Y., Yang, Z., Cohen, W. B., Pflugmacher, D., Lauver, C. L., \& Vankat, J. L. (2009). Distinguishing between live and dead standing tree biomass on the North Rim of Grand Canyon National Park, USA using small-footprint lidar data. Remote Sensing of Environment, 113(11), 2499-2510. http://doi.org/10.1016/j.rse.2009.07.010

Kissling, W. D., \& Carl, G. (2007). Spatial autocorrelation and the selection of simultaneous autoregressive models. Global Ecology and Biogeography, 17, 59-71. http://doi.org/10.1111/j.1466-8238.2007.00334.x

Kolden, C. A., Lutz, J. A., Key, C. H., Kane, J. T., \& van Wagtendonk, J. W. (2012). Mapped versus actual burned area within wildfire perimeters: Characterizing the unburned. Forest Ecology and Management, 286, 38-47. http://doi.org/10.1016/j.foreco.2012.08.020 
Kolden, C. A., Smith, A. M. S., \& Abatzoglou, J. T. (2015). Limitations and utilisation of Monitoring Trends in Burn Severity products for assessing wildfire severity in the USA. International Journal of Wildland Fire, 24(7). http://doi.org/10.1071/WF15082

Koutsias, N., \& Pleniou, M. (2015). Comparing the spectral signal of burned surfaces between Landsat 7 ETM+ and Landsat 8 OLI sensors. International Journal of Remote Sensing, 36(14), 3714-3732. http://doi.org/10.1080/01431161.2015.1070322

Kushla, J. D., \& Ripple, W. J. (1998). Assessing wildfire effects with Landsat thematic mapper data. International Journal of Remote Sensing, 19(13), 2493-2507.

Kwak, D.-A., Chung, J., Lee, W.-K., Kafatos, M., Lee, S. Y., Cho, H.-K., \& Lee, S.-H. (2010). Evaluation for Damaged Degree of Vegetation by Forest Fire using Lidar and a Digital Aerial Photograph. Photogrammetric Engineering and Remote Sensing, 76(3), 277-287.

Lefsky, M. A., Cohen, W. B., Parker, G. G., \& Harding, D. J. (2002). Lidar Remote Sensing for Ecosystem Studies. BioScience, 52(1), 19. http://doi.org/10.1641/00063568(2002)052[0019:LRSFES]2.0.CO;2

Lentile, L. B., Holden, Z. A., Smith, A. M. S., Falkowski, M. J., Hudak, A. T., Morgan, P., ... Benson, N. C. (2006). Remote sensing techniques to assess active fire characteristics and post-fire effects. International Journal of Wildland Fire, 15(3), 319-345. http://doi.org/10.1071/WF05097

Lentile, L. B., Smith, A. M. S., Hudak, A. T., Morgan, P., Bobbitt, M. J., Lewis, S. A., \& Robichaud, P. R. (2009). Remote sensing for prediction of 1-year post-fire ecosystem condition. International Journal of Wildland Fire, 18(5), 594-608. http://doi.org/10.1071/WF07091

Lewis, S. A., Hudak, A. T., Ottmar, R. D., Robichaud, P. R., Lentile, L. B., Hood, S. M., ... Morgan, P. (2011). Using hyperspectral imagery to estimate forest floor consumption from wildfire in boreal forests of Alaska, USA. International Journal of Wildland Fire, 20(2), 255-271. http://doi.org/10.1071/WF09081

Li, F., Bond-Lamberty, B., \& Levis, S. (2014). Quantifying the role of fire in the Earth system Part 2: Impact on the net carbon balance of global terrestrial ecosystems for the 20th century. Biogeosciences, 11(5), 1345-1360. http://doi.org/10.5194/bg-11-1345-2014

López-García, M. J., \& Caselles, V. (1991). Mapping burns and natural reforestation using thematic Mapper data. Geocarto International, 6(1), 31-37. http://doi.org/10.1080/10106049109354290

Lutz, J. A., Larson, A. J., Becker, K. M. L., Furniss, T. J., Blomdahl, M., Germain, S. J., \& Swanson, M. E. (2016). Post Rim Fire Assessment of Fuel Consumption and Mortality in the Yosemite Forest Dynamics Plot. Final Report to the National Park Service Cooperative Agreement.

Mahiny, A. S., \& Turner, B. J. (2007). A comparison of four common atmospheric correction methods. Photogrammetric Engineering \& Remote Sensing, 73(4), 361-368. http://doi.org/10.14358/PERS.73.4.361

McCarley, T. R. (2016). Estimation of Landscape-scale Fire Effects from Multi-temporal LiDAR (Master's thesis). University of Idaho, Moscow, Idaho.

McGaughey, R. J. (2014). FUSION/LDV: Software for LIDAR Data Analysis and Visualization. USDA Forest Service, Pacific Northwest Research Station.

Meigs, G. W., Donato, D. C., Campbell, J. L., Martin, J. G., \& Law, B. E. (2009). Forest Fire Impacts on Carbon Uptake, Storage, and Emission: The Role of Burn Severity in the 
Eastern Cascades, Oregon. Ecosystems, 12(8), 1246-1267. http://doi.org/10.1007/s10021009-9285-x

Meigs, G. W., Turner, D. P., Ritts, W. D., Yang, Z., \& Law, B. E. (2011). Landscape-Scale Simulation of Heterogeneous Fire Effects on Pyrogenic Carbon Emissions, Tree Mortality, and Net Ecosystem Production. Ecosystems, 14(5), 758-775. http://doi.org/10.1007/s10021011-9444-8

Meigs, G. W., Zald, H. S. J., Campbell, J. L., Keeton, W. S., \& Kennedy, R. E. (2016). Do insect outbreaks reduce the severity of subsequent forest fires? Environmental Research Letters, 11(4), 1-10. http://doi.org/10.1088/1748-9326/11/4/045008

Miller, J. D., Safford, H. D., Crimmins, M., \& Thode, A. E. (2009). Quantitative Evidence for Increasing Forest Fire Severity in the Sierra Nevada and Southern Cascade Mountains, California and Nevada, USA. Ecosystems, 12(1), 16-32. http://doi.org/10.1007/s10021-0089201-9

Miller, J. D., \& Thode, A. E. (2007). Quantifying burn severity in a heterogeneous landscape with a relative version of the delta Normalized Burn Ratio (dNBR). Remote Sensing of Environment, 109(1), 66-80. http://doi.org/10.1016/j.rse.2006.12.006

Miller, J. D., \& Yool, S. R. (2002). Mapping forest post-fire canopy consumption in several overstory types using multi-temporal Landsat TM and ETM data. Remote Sensing of Environment, 82(2-3), 481-496. http://doi.org/10.1016/S0034-4257(02)00071-8

Moody, J. A., Martin, D. A., Haire, S. L., \& Kinner, D. A. (2008). Linking runoff response to burn severity after a wildfire. Hydrological Processes, 22(13), 2063-2074. http://doi.org/10.1002/hyp.6806

Morgan, P., Keane, R. E., Dillon, G. K., Jain, T. B., Hudak, A. T., Karau, E. C., ... Strand, E. K. (2014). Challenges of assessing fire and burn severity using field measures, remote sensing and modelling. International Journal of Wildland Fire, 23(8), 1045. http://doi.org/10.1071/WF13058

Nagelkerke, N. J. D. (1991). A note on a general definition of the coefficient of determination. Biometrika, 78(3), 691-692. http://doi.org/10.1093/biomet/78.3.691

Pace, R. K., \& LeSage, J. P. (2004). Chebyshev approximation of log-determinants of spatial weight matrices. Computational Statistics and Data Analysis, 45(2), 179-196. http://doi.org/10.1016/S0167-9473(02)00321-3

Parks, S., Dillon, G., \& Miller, C. (2014). A New Metric for Quantifying Burn Severity: The Relativized Burn Ratio. Remote Sensing, 6(3), 1827-1844. http://doi.org/10.3390/rs6031827

Patterson, M. W., \& Yool, S. R. (1998). Mapping Fire-Induced Vegetation Mortality Using Landsat Thematic Mapper Data. Remote Sensing of Environment, 65(2), 132-142. http://doi.org/10.1016/S0034-4257(98)00018-2

Prichard, S. J., \& Kennedy, M. C. (2014). Fuel treatments and landform modify landscape patterns of burn severity in an extreme fire event. Ecological Applications, 24(3), 571-590. http://doi.org/10.1890/13-0343.1

R Development Core Team. (2014). A language and environment for statistical computing. Vienna, Austria: R Foundation for Statistical Computing. Retrieved from https://www.rproject.org/

Randerson, J. T., Chen, Y., van der Werf, G. R., Rogers, B. M., \& Morton, D. C. (2012). Global burned area and biomass burning emissions from small fires. Journal of Geophysical 
Research: Biogeosciences, 117(4). http://doi.org/10.1029/2012JG002128

Reddy, A. D., Hawbaker, T. J., Wurster, F., Zhu, Z., Ward, S., Newcomb, D., \& Murray, R. (2015). Quantifying soil carbon loss and uncertainty from a peatland wildfire using multitemporal LiDAR. Remote Sensing of Environment, 170, 306-316.

http://doi.org/10.1016/j.rse.2015.09.017

Riaño, D., Chuvieco, E., Condés, S., González-Matesanz, J., \& Ustin, S. L. (2004). Generation of crown bulk density for Pinus sylvestris L. from lidar. Remote Sensing of Environment, 92(3), 345-352. http://doi.org/10.1016/j.rse.2003.12.014

Riaño, D., Meier, E., \& Allgower, B. (2003). Modeling airborne laser scanning data for the spatial generation of critical forest parameters in fire behavior modeling. Remote Sensing of Environment, 86(2), 177-186. http://doi.org/10.1016/S0034-4257(03)00098-1

Robichaud, P. R., Lewis, S. A., Brown, R. E., \& Ashmun, L. E. (2009). Emergency Post-fire Rehabilitation Treatment Effects on Burned Area Ecology and Long-term Restoration. Fire Ecology Special Issue, 5(1), 115-128.

Rogan, J., \& Yool, S. (2001). Mapping fire-induced vegetation depletion in the Peloncillo Mountains, Arizona and New Mexico. International Journal of Remote Sensing, 22(16), 3101-3121. http://doi.org/10.1080/01431160152558279

Rouse, J. W., Haas, R. H., Deerling, D. W., Schell, J. A., \& Harlan, J. C. (1974). Monitoring the vernal advancement and retrogradation (green wave effect) of natural vegetation. Greenbelt, MD: NASA/GSFC Type III Final Report.

Roy, D. P., Boschetti, L., \& Smith, A. M. S. (2013). Satellite Remote Sensing of Fires. In C. M. Belcher \& G. Rein (Eds.), Fire Phenomena and the Earth System: an interdisciplinary guide to fire science (pp. 77-93). Oxford: John Wiley \& Sons. http://doi.org/10.1002/9781118529539.ch5

Roy, D. P., Boschetti, L., \& Trigg, S. N. (2006). Remote Sensing of Fire Severity: Assessing the Performance of the Normalized Burn Ratio. IEEE Geoscience and Remote Sensing Letters, 3(1), 112-116. http://doi.org/10.1109/LGRS.2005.858485

Seielstad, C. A., \& Queen, L. P. (2003). Using airborne laser altimetry to determine fuel models for estimating fire behaviour. Journal of Forestry, 101(4), 10-15.

Skowronski, N. S., Clark, K. L., Gallagher, M., Birdsey, R. A., \& Hom, J. L. (2014). Airborne laser scanner-assisted estimation of aboveground biomass change in a temperate oak-pine forest. Remote Sensing of Environment, 151, 166-174. http://doi.org/10.1016/j.rse.2013.12.015

Smith, A. M. S., Drake, N. A., Wooster, M. J., Hudak, A. T., Holden, Z. A., \& Gibbons, C. J. (2007). Production of Landsat ETM+ reference imagery of burned areas within Southern African savannahs: comparison of methods and application to MODIS. International Journal of Remote Sensing, 28(12), 2753-2775. http://doi.org/10.1080/01431160600954704

Smith, A. M. S., Eitel, J. U. H., \& Hudak, A. T. (2010). Spectral analysis of charcoal on soils: Implicationsfor wildland fire severity mapping methods. International Journal of Wildland Fire, 19(7), 976-983. http://doi.org/10.1071/WF09057

Smith, A. M. S., Falkowski, M. J., Hudak, A. T., Evans, J. S., Robinson, A. P., \& Steele, C. M. (2009). A cross-comparison of field, spectral, and lidar estimates of forest canopy cover. Canadian Journal of Remote Sensing, 35(5), 447-459. http://doi.org/10.5589/m09-038

Smith, A. M. S., Kolden, C. A., Tinkham, W. T., Talhelm, A. F., Marshall, J. D., Hudak, A. T., ... Gosz, J. R. (2014). Remote sensing the vulnerability of vegetation in natural terrestrial 
ecosystems. Remote Sensing of Environment, 154, 322-337.

http://doi.org/10.1016/j.rse.2014.03.038

Smith, A. M. S., Kolden, C. A., Paveglio, T. B., Cochrane, M. A., Bowman, D. M. J. S., Moritz, M. A., ... Abatzoglou, J. A. (2016a). The science of firescaoe: achieving fire resilient communities, Bioscience, 66(2), 130-146. doi: 10.1093/biosci/biv182

Smith, A. M. S., Sparks, A. M., Kolden, C. A., Abatzoglou, J. T., Talhelm, A. F., Johnson, D. M., ... Kremens, R. J. (2016b). Towards a new paradigm in fire severity research using dose-response experiments. International Journal of Wildland Fire, 25(2), 158-166. http://doi.org/10.1071/WF15130

Soverel, N. O., Perrakis, D. D. B., \& Coops, N.C. (2010) Estimating burn severity from Landsat dNBR and RdNBR indices across western Canada. Remote Sensing of Environment, 114 (9), 1896-1909.

Sparks, A. M., Boschetti, L., Smith, A. M. S., Tinkham, W. T., Lannom, K. O., \& Newingham, B. A. (2015). An accuracy assessment of the MTBS burned area product for shrub-steppe fires in the northern Great Basin, United States. International Journal of Wildland Fire, 24(1), 70. http://doi.org/10.1071/WF14131

Sparks, A. M., Kolden, C. A., Talhelm, A. F., Smith, A. M. S., Apostol, K. G., Johnson, D. M., \& Boschetti, L. (2016). Spectral Indices Accurately Quantify Changes in Seedling Physiology Following Fire: Towards Mechanistic Assessments of Post-Fire Carbon Cycling. Remote Sensing, 8(7), 572. http://doi.org/10.3390/rs8070572

Tinkham, W. T., Smith, A. M. S., Hoffman, C., Hudak, A. T., Falkowski, M. J., Swanson, M. E., \& Gessler, P. E. (2012). Investigating the influence of LiDAR ground surface errors on the utility of derived forest inventories. Canadian Journal of Forest Research, 42, 413-422. http://doi.org/10.1139/x11-193

Tinkham, W. T., Smith, A. M. S., Marshall, H. P., Link, T. E., Falkowski, M. J., \& Winstral, A. H. (2014). Quantifying spatial distribution of snow depth errors from LiDAR using Random Forest. Remote Sensing of Environment, 141, 105-115. http://doi.org/10.1016/j.rse.2013.10.021

Trigg, S., \& Flasse, S. (2001). An evaluation of different bi-spectral spaces for discriminating burned shrub-savannah. International Journal of Remote Sensing, 22(13), 2641-2647. http://doi.org/10.1080/01431160110053185

Turner, M. G., Hargrove, W. W., Gardner, R. H., \& Romme, W. H. (1994). Effects of Fire on Landscape Heterogeneity in Yellowstone National Park, Wyoming. Journal of Vegetation Science, 5(5), 731-742.

van Wagtendonk, J. W., Root, R. R., \& Key, C. H. (2004). Comparison of AVIRIS and Landsat ETM+ detection capabilities for burn severity. Remote Sensing of Environment, 92(3), 397408. http://doi.org/10.1016/j.rse.2003.12.015

Vepakomma, U., St-Onge, B., \& Kneeshaw, D. (2008). Spatially explicit characterization of boreal forest gap dynamics using multi-temporal lidar data. Remote Sensing of Environment, 112(5), 2326-2340. http://doi.org/10.1016/j.rse.2007.10.001

Veraverbeke, S., Lhermitte, S., Verstraeten, W. W., \& Gooseens, R. (2010) The temporal dimension of difference Normalized Burn Ratio (dNBR) fire/burn severity studies: The case of the large 2007 Pelopennese wildfires in Greece, Remote Sensing of Environment, 114 (11), 2548-2563.

Wang, C., \& Glenn, N. F. (2009). Estimation of fire severity using pre- and post-fire LiDAR data 
in sagebrush steppe rangelands. International Journal of Wildland Fire, 18(7), 848-856. http://doi.org/10.1071/WF08173

White, J. D., Ryan, K. C., Key, C. C., \& Running, S. W. (1996). Remote Sensing of Forest Fire Severity and Vegetation Recovery. International Journal of Wildland Fire, 6(3), 125-136.

Whittier, T. R., \& Gray, A. N. (2016). Tree mortality based fire severity classification for forest inventories: A Pacific Northwest national forests example. Forest Ecology and Management, 359, 199-209. http://doi.org/10.1016/j.foreco.2015.10.015

Wimberly, M. C., Cochrane, M. A., Baer, A. D., \& Pabst, K. (2009). Assessing fuel treatment effectivness using satellite imagery and spatial statistics. Ecological Applications, 19(6), 1377-1384. Retrieved from http://www.jstor.org/stable/40346253

Wimberly, M. C., \& Reilly, M. (2007). Assessment of fire severity and species diversity in the southern Appalachians using Landsat TM and ETM+ imagery. Remote Sensing of Environment, 108(2), 189-197. http://doi.org/10.1016/j.rse.2006.03.019

Wing, B. M., Ritchie, M. W., Boston, K., Cohen, W. B., Gitelman, A., \& Olsen, M. J. (2012). Prediction of understory vegetation cover with airborne lidar in an interior ponderosa pine forest. Remote Sensing of Environment, 124, 730-741. http://doi.org/10.1016/j.rse.2012.06.024

Wing, B. M., Ritchie, M. W., Boston, K., Cohen, W. B., \& Olsen, M. J. (2015). Individual snag detection using neighborhood attribute filtered airborne lidar data. Remote Sensing of Environment, 163, 165-179. http://doi.org/10.1016/j.rse.2015.03.013

Wulder, M. A., White, J. C., Alvarez, F., Han, T., Rogan, J., \& Hawkes, B. (2009). Characterizing boreal forest wildfire with multi-temporal Landsat and LIDAR data. Remote Sensing of Environment, 113(7), 1540-1555. http://doi.org/10.1016/j.rse.2009.03.004

Zhu, Z., Key, C. H., Ohlen, D., \& Benson, N. (2006). Mapping Algorithms for Different Ecosystems. Final Report to the Joint Fire Science Program. 